\title{
El romance en pliego de Las princesas encantadas (s. XVIII) y las variantes hispánicas de dos cuentos maravillosos: Three Stolen Princesses (ATU, 301) y Goldener (ATU, 314) ${ }^{*}$
}

\author{
Rafael BELTRÁN \\ (Universitat de València) \\ rafael.beltran@uv.es \\ ORCID ID: 0000-0002-9346-3105
}

\begin{abstract}
The Spanish ballad Las princesas encantandas $y$ delealtad entre hermanos was printed as a chapbook with three parts in the 18th century and throughout the 19th century. This paper aims to analyze this ballad as a folktale and fairy tale which includes sequences and folk motifs found in ATU 301 (The Three Stolen Princesses, better known as John the Bear in Hispanic versions) and ATU 314 (Goldener). Its plot will be compared with a tale in One Thousand and One Nights (modern tale, introduced by Mardrus in the 1889 version), and with three Hispanic tales: El caballo de siete colores, written by Juan de Ariza (1848), Mercè Mercè, folktale collected by Antoni Alcover (1896), and the Philippine awit (versified story) Juan Tiñoso. The comparison makes it possible to raise a hypothesis about the relationship between all these tales and the contexts of distribution of Las princesas encantadas.
\end{abstract}

KEYWORDS: Las princesas encantadas, chapbook, fairy tale, folktale, Three Stolen Princesses, Goldener, Juan de Ariza, Antoni Alcover, awit.
RESUMEN. El romance en pliego de cordel de Las princesas encantandas y delealtad entre hermanos se imprimió en tres partes a partir del siglo XVIII y durante el siglo XIX. Analizamos, en primer lugar, el argumento del romance como cuento popular y maravilloso, que agrupa secuencias y motivos folclóricos de ATU 301 (The Three Stolen Princesses, más conocido en versiones hispánicas como Juan el Oso) y ATU, 314 (Goldener). En segundo lugar, se compara su argumento con el de un cuento de Las mil y una noches (cuento moderno, introducido en la versión alterada por Mardrus, en 1889) y con los tres cuentos hispánicos (o de origen hispánico) más relacionados: El caballo de siete colores, de Juan de Ariza (1848), En Mercè-Mercè, rondalla recopilada por Antoni Alcover (1896) y el awit (relato versificado) filipino Juan Tiñoso. La comparación permite llegar a unas hipótesis en torno a la filiación de todos estos cuentos y en torno a los contextos de distribución del romance y cuento de Las princesas encantadas.

PALABRAS-CLAVE: Las princesas encantadas, pliego suelto, pliego de cordel, cuento popular, cuento maravilloso, Three Stolen Princesses, Goldener, Juan de Ariza, Antoni Alcover, awit.

\section{EL PLIEGO DE CORDEL DE LAS PRINCESAS ENCANTADAS Y DESLEALTAD DE HERMANOS}

El romance en pliego de cordel de Las princesas encantadas y deslealtad de hermanos [en adelante, $L P E$ ] se imprimió y distribuyó, en principio en tres partes, una por pliego suelto, a partir de finales del siglo XVIII y durante el siglo XIX. Agustín Durán, sin embargo, lo editó dividido en dos partes, correspondientes a los núms. 1263

\footnotetext{
* El presente trabajo se ha realizado en el marco del Proyecto de Investigación FFI2014-51781-P, "Parnaseo (Servidor Web de Literatura Española)", integrado en el «Programa estatal de fomento de la investigación científica y técnica de excelencia» del Ministerio español de Economía y Competitividad.
} 
y 1264 de su Romancero general (1849-1851), agrupando en dos los tres pliegos. ${ }^{1}$ En el romance, una princesa, encantada y encerrada junto a sus hermanas en una torre por su padre el rey, es desencantada por el pequeño de los tres hermanos que han acudido en su rescate. El liberador queda encerrado por culpa de sus hermanos, pero logra escapar de la torre gracias a un caballo mágico. Disfrazado de pastor, llega al palacio de la princesa rescatada, que lo reconocerá por una gargantilla que le había regalado al ser liberada. Se casan pero el héroe tendrá que superar dos pruebas en lugares remotos, que permitan curar a su suegro de dos graves enfermedades, y finalmente salvar el reino venciendo a sus enemigos.

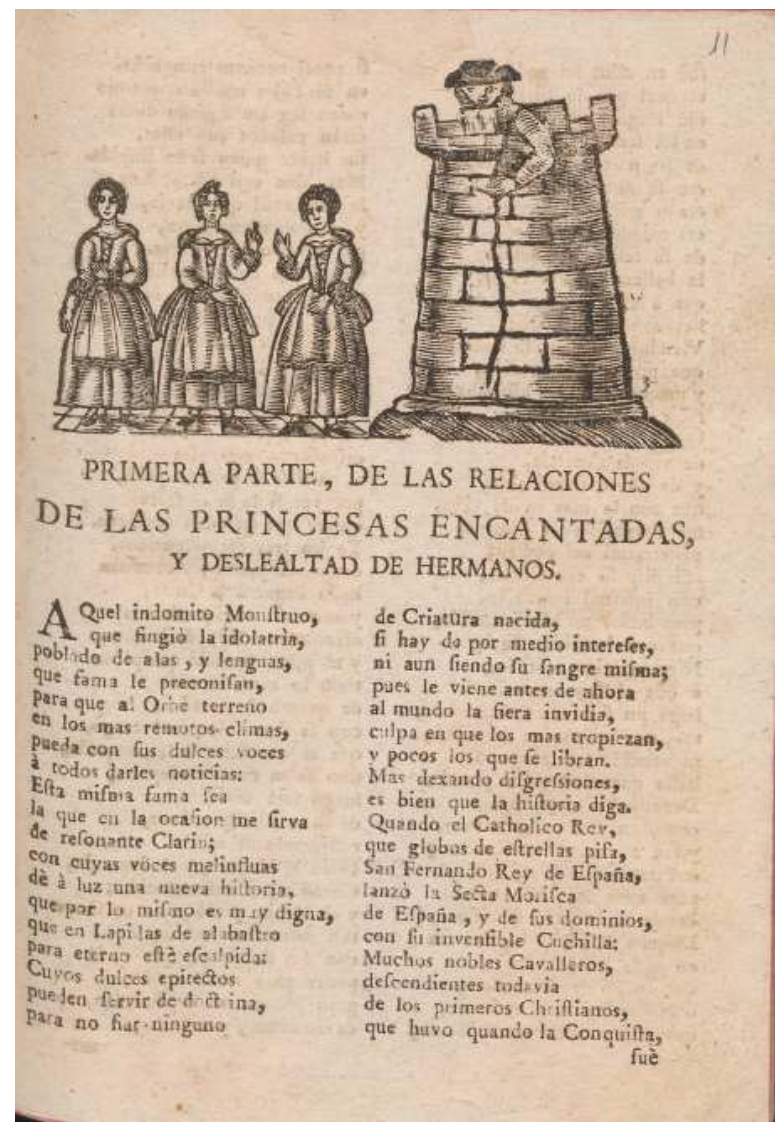

Figura 1

Cambridge University Library

(item no. 11 in volume 8000.c.979)

\footnotetext{
${ }^{1}$ En la versión anterior del Romancero caballeresco, publicada por Durán en dos partes, en 1832, no aparecía el romance (vid. Gies, 1975: 92-119; y De la Campa, 2007). Los referentes principales en el estudio de los pliegos sueltos a partir del XVIII, Caro Baroja (1969), Aguilar Piñal (1972), García de Enterría (1973, 1983), Marco (1977), Mendoza (2001), entre otros, mencionan en algún momento varios de los pliegos conocidos de LPE. Hoy, años después, gracias a la digitalización de textos, en concreto pliegos, en bibliotecas sobre todo españolas y británicas, se puede conocer y consultar un fondo mucho más extenso y con mayores facilidades. Sin embargo, no entraremos directamente, en este trabajo, en el detalle de la enumeración, descripción y estudios de los pliegos conocidos (con sus imprentas y contextos de producción editorial particulares), aspectos que serán abordados, junto con la edición crítica del texto de $L P E$, en un trabajo posterior, en estos momentos en preparación.
} 
Aun no siendo del todo extraña al romancero vulgar impreso en los siglos XVIII y XIX la temática estrictamente maravillosa que presentan sus versos, los ingredientes fantásticos de $L P E$ son tantos y están distribuidos de manera tan insólita — como los de un cuento de hadas de tradición oral - que extraña que se expandieran en España con anterioridad a la difusión de los Kinder- und Hausmärchen (1812-1815) de los hermanos Grimm, que significaron el despegue de la definitiva apreciación por los fairy tales en Europa y América. El desarrollo del argumento no sólo no concuerda con ninguna combinación conocida de motivos habituales en el romancero viejo, o en el romancero nuevo y vulgar (los clasificados por Goldberg [2000]), sino que agrupa secuencias y motivos folclóricos novedosos, muchos de ellos coincidentes, eso sí, con los que se presentan en varios tipos del cuento folclórico universal, en especial los clasificados por Hans-Jörg Uther como ATU, 301 y ATU, 314. En el primero, ATU 301, The Three Stolen Princesses, más conocido en versiones hispánicas como Juan el $O s o$, el héroe es abandonado en un pozo (si bien aquí, en $L P E$, se trata de una torre) por sus compañeros traicioneros, que pueden ser sus hermanos como sucede en la historia bíblica de José. En el segundo, ATU, 314, Goldener, el héroe vence sus carencias de partida, ayudado por un caballo mágico, y alcanza los remedios mágicos que han de curar al padre de la princesa que pretende. ${ }^{2}$

Un texto, así, tan supuestamente nimio como el de $L P E$, de apenas 1000 versos en el total de sus tres partes, portador de una historia aparentemente muy simple de princesas rescatadas por un héroe valiente y sagaz, plantea una serie de incertidumbres y retos a la curiosidad del historiador de la literatura, de la imprenta y del libro, que hacen necesario su examen más detenido, para tratar de esclarecer hasta donde nos sea posible los orígenes de sus fragmentos constitutivos e iluminar los contextos de su publicación y difusión.

Éste es el argumento más detallado de $L P E$ :

[1] [Princesas liberadas y hermano traicionado] En las llamadas «Relaciones de las princesas encantadas y deslealtad de hermanos», se cuenta cómo en tiempos de «San Fernando, rey de España», que expulsó a los moros de España, vivía en la región oriental de Siria uno de éstos, Clotaldo, descendiente de «los primeros alarbes», felizmente casado y con tres hermosas hijas. Clotaldo, pensando que nadie era merecedor de sus hijas, hace construir un castillo impenetrable para encerrarlas en él. Y manda a un «mágico sabio» para que con «nigrománticos enredos» logre un encantamiento de manera que no puedan ser vistas. Las hijas serán custodiadas por tres caballos («o satánicas arpías»). Clotaldo promulga un decreto, según el cual los nobles que puedan entrar en la torre y desencantar a sus hijas se podrán casar con ellas.

Tres hermanos «de ilustre genealogía», nacidos en Dinamarca, acuden a rescatarlas; los dos mayores piden al rey «caballos y armas lucidas», pero el tercero simplemente solicita que le proporcionen un carro con dos bueyes, cargado con vituallas suficientes, más clavos y una cuerda larga. Los dos mayores llegan al edificio y se desaniman al ver «torre tan fortalecida»; cavilan para intentar escalarla, pero acaban desistiendo. De regreso, tratan de disuadir de un empeño vano a su hermano menor, que llega «muy poco a poco, en su carro», pero él insiste en

\footnotetext{
2 Pero también encontraremos elementos argumentales o motivos, que más adelante hemos de comentar, de ATU, 310, The Maiden in the Tower, es decir, del cuento clásico de Rapunzel, la doncella rescatada por el príncipe; de ATU, 304, The Dangerous Night-Watch, en el que el héroe va a buscar remedio para la ceguera de su padre; de ATU, 530, The Princess on the Glass Mountain, donde la hija del rey es ofrecida a quien pueda subir a la cima de una montaña de cristal o mármol, y coger una manzana de oro; y, finalmente, de ATU, 550, Bird, Horse and Princess, muy cercano al siguiente tipo, ATU, 551, Water of Life, en los que el héroe, como en ATU, 314, se enfrenta a sus hermanos a la hora de encontrar la poción (agua u otra) que ha de curar a su padre (o a su suegro, como en $L P E$ ).
} 
intentarlo; los hermanos retroceden entonces de nuevo hasta el pie de la torre acompañándolo. En efecto, el muchacho, con ayuda de la cuerda, y con los clavos y un martillo en la cintura, consigue escalar la torre. Cuando llega a la cima, encuentra a las «tres hermosísimas ninfas», que le dicen que para ser desencantadas bastará con que quite una cerda a cada caballo, porque en éstas reside el hechizo. Conseguida la tarea, las hermanas quedan libres. Las ayuda a bajar, una a una, con la cuerda, pero antes de descender la última, la menor le dona una gargantilla, pidiéndole que no la deje nunca puesto que le puede servir en un futuro para liberarse como las ha liberado él a ellas. Cuando han descendido las tres, los desaprensivos hermanos mayores le arrebatan al pequeño la cuerda con la que tenía que bajar, «con infernal avaricia, / conociendo que su hermano / todo el premio merecía». Y se van, abandonándolo: «envidiosos dispusieron / ponerse luego en huida». Al llegar a la corte, guardan el secreto de lo sucedido y el rey, admirado, dispone el matrimonio de sus dos primeras hijas con los dos hermanos mayores.

[2] [Huida del héroe con el caballo mágico] La Segunda Parte del romance se inicia cuando, descubierta la maldad, el héroe, el hijo menor, queda «afligido y pesaroso, / melancólico y suspenso». Pero reacciona y acude a uno de los caballos encerrados con las princesas y gracias a la gargantilla que le ha regalado la menor, consigue que éste dé «un brinco tan formidable» que le hará salir volando de la torre y llegar enseguida a un «áspero desierto». Allí encuentra a un pastor («un ganadero») que le dice que se halla en tierra de «suecos». El héroe le pide intercambiar vestidos y se disfraza de «ganadero», cubriéndose con pieles y tapando los cabellos con una gorra hecha con piel de cordero. Y así, «tan tosco como grosero, / pidiendo a algunos limosna, / pasaba de pueblo en pueblo». [3] [El héroe en palacio: reconocimiento y matrimonio, con disconformidad del rey] Cuando llega al pueblo de las princesas, centenares de millas distante, no sólo ha cambiado la cara y la vestimenta, sino que, además, finge llamarse Juan y se hace el loco, por lo que le llaman «Juanillo el loco». Mientras, en la corte, la hija pequeña, que ha quedado sin casar y que no olvida a su rescatador, le pedirá a su padre dos condiciones para casarse. En primer lugar, que convoque unos torneos con el fin de elegir al vencedor para contraer matrimonio. El «loco fingido» de Juanillo hace lumbre con una primera cerda de su caballo mágico: entonces aparece un caballo con dos sirvientes; con esos auxiliares, él combate y gana el torneo. La tarde segunda quema la segunda cerda y se le aparece otro caballo con seis criados con sus libreas; Juanillo vence a todos en la carrera. La tarde tercera, vuelve a quemar la cerda y aparece un caballo negro con doce criados, de terciopelo y carmesí; pese al recinto amurallado construido, desaparece después de haber vencido. En segundo lugar (segunda condición) y dado que Juanillo ha desaparecido sin darse a conocer, la princesa pide a su padre que un joyero («alquimista») haga una gargantilla como la que entregó al caballero de Dinamarca que la rescató. Por su parte, éste ha entrado en la corte como «mandadero» del rey. El rey se desespera porque pasan los días y el alquimista no logra poder reproducir la preciosa gargantilla encargada y diseñada por su hija. Juanillo, el «mandadero», le pregunta al rey por sus cuitas y le promete que él solucionará el problema. Se encierra en una habitación y, para sorpresa del monarca, que lo tiene por loco, aparecerá con una gargantilla como la pedida por su hija. Ella acepta casar con quienquiera que sea que la haya sabido hacer. Cuando el «lapidario» Juanillo y la princesa se encuentran, se reconocen, pero guardan el secreto. Y el rey no tiene más remedio que consentir, pese a los «vituperios» de hijas y cuñados, el matrimonio de ambos.

[4] [El héroe ayuda al rey: superación de tres pruebas] En la Tercera Parte, el rey, avergonzado del matrimonio de su hija con el criado loco, manda que la pareja recién casada habite un «tosco albergue», ubicado fuera del palacio. Tanto es el disgusto de Clotaldo que enferma gravemente: queda «ciego sin sentido». [4a. Agua mágica] Los médicos dicen que el único remedio para su cura estaría en las aguas de una fuente nacida en los montes de Esclavonia, rodeada de peligrosas alimañas. El hermano pequeño se apresura a obtenerla, cabalga veloz en el caballo mágico y toma el agua prescrita. Al regreso, se encuentra con sus hermanos, que le ofrecen dinero a cambio del agua tomada. Él les pide, en vez de recompensa monetaria, que le entreguen dos peras que les había regalado el rey. Consienten, regresan a la corte, aportan el agua y el rey se cura gracias al líquido. [4b. Leche de leona] Sin embargo, al 
poco vuelve a enfermar y los médicos dicen que sólo le puede curar la leche (el «néctar») de una de las leonas de los desiertos de Albania. De nuevo, Juanillo coge el segundo caballo, se planta enseguida allí y coge la leche de leona. Y de nuevo al regresar sus hermanos le ofrecen lo que sea a cambio de que les ceda el remedio que puede sanar al rey. Él les exige esta vez que se dejen desorejar, a lo que, pese a las reticencias iniciales, acaban accediendo. Como la vez primera, gracias en este caso a la leche de leona, el rey se cura. [4c. Ayuda militar] Pero ahora, en lo que será la tercera prueba, entra el rey en guerra y les pide a sus yernos que acudan al campo enemigo como espías. Por tercera vez se adelanta Juanillo, con el tercer caballo; hace estragos en el enemigo, los vence y regresa portando las banderas y una espada como señales de la victoria. Y de regreso encuentra a los hermanos, de quienes se burla: «-Amigos, ya venís tarde. / Que siempre pierde el tardío». En esta ocasión lo que les pedirá, a cambio de los pendones de victoria, será que se dejen marcar con un hierro como esclavos suyos. Ellos consienten, él les deja una marca en la parte izquierda de la espalda, y regresan. El rey celebra con sus yernos la victoria, que cree que les debe a ellos, y cobra tal odio a su yerno pequeño que decide desterrarlo. [5] [Regreso y reivindicación] Juanillo le suplica entonces que, antes de partir, reúna a todos los grandes en palacio. Allí se quita definitivamente el disfraz y se viste apropiadamente. Ante todos, descubre que él ha sido quien liberó a las princesas, primero; quien logró el agua curativa, después, como demuestra enseñando las peras obtenidas a cambio; quien obtuvo la leche de leona, como prueba obligando a destocarse a sus hermanos, que se muestran desorejados; y quien había ganado la guerra, como demuestra haciendo ver las marcas de hierro en las espaldas de los hermanos. Declara al final, sin embargo, que perdona a sus hermanos. Y el rey, entonces, lo nombra heredero: «de todos / mis bienes heredativo». El romance concluye con moraleja: «Estos son los merecidos / que consiguen los avaros / que emprenden casos indignos; / Y así, quien todo lo quiere / todo lo pierde, y es fijo». Y con un explicit, que incluye el nombre de su autor, seguido de dos tópicos del exordio, el del manuscrito encontrado y el de la escritura por encargo: «Donde Alonso de Morales, / que este suceso halló escrito, / quiso reducirlo a versos, / al mandado de un amigo».

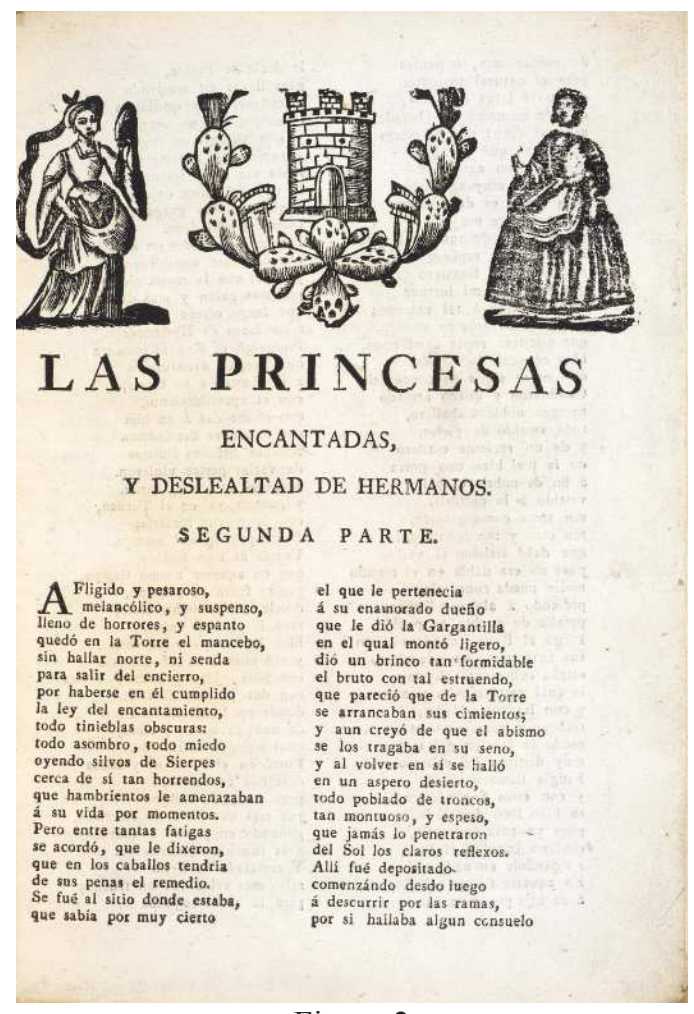

Figura 2

Impreso B (Biblioteca privada de R. Beltrán) 
A título simplemente orientativo, podríamos agrupar las ediciones conocidas del pliego en ocho. Por orden cronológico: A (h. 1770-1790): se conservan al menos cinco ejemplares - con algunas variantes de impresión entre ellos- de tres pliegos de 8 págs. (Primera, Segunda y Tercera Parte) con la versión más antigua de LPE, en distintas bibliotecas españolas y europeas, sin lugar ni fecha de impresión [figura 1]; B (h. 17991820): se conservan al menos otros cinco ejemplares, sin lugar ni fecha de impresión [figura 2]; C (1820-1823): Madrid, Imprenta de Marés, se conservan al menos tres ejemplares; D (h. 1830): Murcia, Imprenta de José Santa María; E: Córdoba, ejemplares de las Imprentas de Rafael García Rodríguez y Luis de Ramos (1830-1840); F: se trataría de la edición en el vol. II del Romancero General de Agustín Durán (1851); G: Madrid, Imprenta de Marés (1851); y H: Valladolid, Imprenta de Santarén (1852 y 1860) [figura 3$]^{3}$

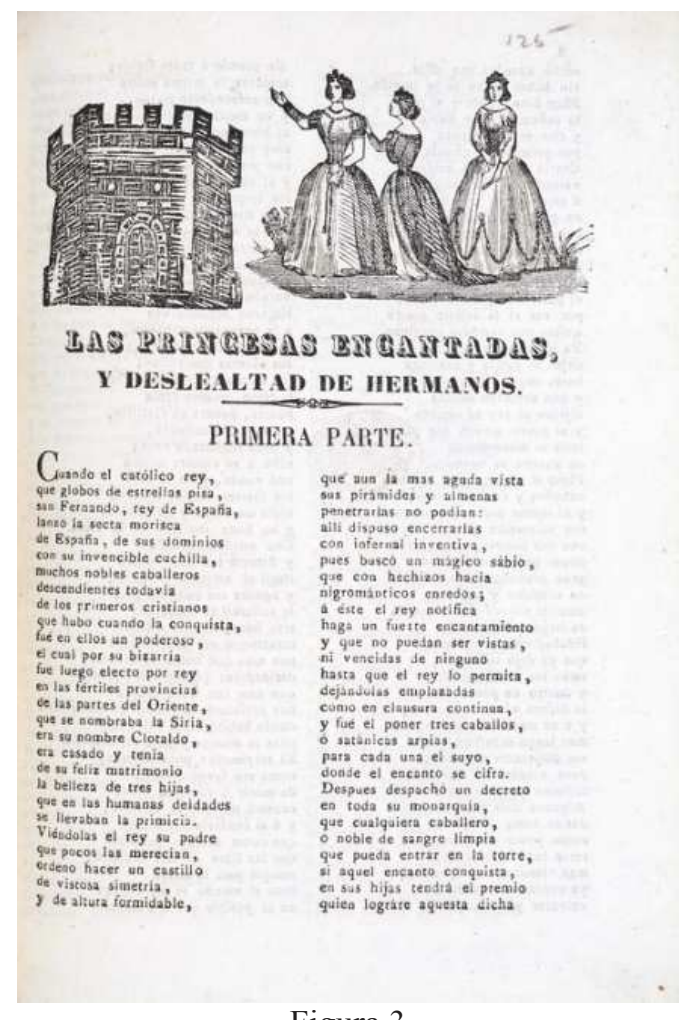

Figura 3

Valladolid, Imprenta de Santarén, 1852

(British Library, Item no. T125 in volume 1074.g.24.)

El nombre de Alonso de Morales aparece al final de cada una de las tres partes originales de LPE. Alonso Pablo de Morales (razones métricas pudieron obligar a eliminar el segundo nombre de pila) fue el autor de al menos cinco romances que se difundieron en pliegos desde finales del XVIII: además de LPE, La española inglesa (versión en romance de la novela cervantina que lleva el mismo título), ${ }^{4}$ La cautiva de

\footnotetext{
${ }^{3}$ A partir de la edición de Durán, que distribuye el texto en dos partes, los impresos posteriores en pliego $(\mathrm{G}$ y $\mathrm{H})$ siguen ese esquema y publican el texto en dos pliegos, correspondientes a sendas partes.

${ }^{4}$ La primera identificación del autor de $L P E$ con el Alonso Pablo Morales, autor de la versión en romance de La española inglesa, la novela ejemplar de Miguel de Cervantes, la propuso Porro Herrera (2002: 288), en su trabajo sobre los folios de un nuevo pliego encontrado de este romance.
} 
Sevilla, ${ }^{5}$ El frayle fingido ${ }^{6}$ y Florisela. Hay suficientes indicios de autoría común, por tanto, en los pliegos, empezando por la declaración explícita, que no es necesaria y ni siquiera frecuente en los pliegos de cordel. Hay imprentas comunes e importantes detalles coincidentes, como el nombre del inglés raptor de la protagonista de La española inglesa, Clotaldo, el mismo que Morales adjudica al rey y padre de las hijas encerradas en la torre de $L P E$. Y el año de 1777 para uno de los pliegos de La cautiva de Sevilla, en concreto, nos da la fecha más antigua que tenemos para otra obra de su autor y, de ahí, una posible fecha aproximativa para los primeros impresos de $L P E$.

\section{El primer componente (ATU, 301, The ThreE Stolen PrincesSes): tres} HERMANOS AL RESCATE DE LAS PRINCESAS ENCERRADAS

Clotaldo, el rey que encierra a sus tres hijas en la torre inexpugnable, procede de los descendientes de la expulsión de musulmanes de España («la secta morisca»), pero también de «descendientes todavía / de los primeros cristianos / que hubo cuando la conquista», en «las fértiles provincias / de las partes del oriente», y en concreto en Siria, fue elegido rey. El Clotaldo del romance es, por tanto, rey de Siria, provincia de Oriente, en tiempos de rey Fernando III de Castilla ( «San Fernando, rey de España»). La raíz del nombre (Clotardo, en algunas versiones) emparentaría fonéticamente con la de los reyes merovingios y, sobre todo, con Clotario (Clotario I [511-561], bisnieto de Meroveo y uno de los cuatro hijos de Clodoveo I, el famoso rey franco).

Ya en el ámbito no legendario, sino estrictamente literario, Clotaldo nos recuerda el nombre del ayo de Basilio y padre de Rosaura en La vida es sueño de Calderón de la Barca. ${ }^{7}$ Sin embargo, el nombre que más decididamente tuvo que influir para denominar al padre de la muchacha en el romance tuvo que ser el Clotaldo de La española inglesa de Miguel de Cervantes. Clotaldo, en ella, es el raptor de la gaditana Isabel, que con siete años es llevada a Inglaterra, donde vivirá como criada de su esposa. Por tanto, parece lógico trasladar el nombre del inglés raptor de la protagonista de la novela

\footnotetext{
${ }^{5}$ La cautiva de Sevilla (Romance que intitula: La Cautiva de Sevilla..., por Alonso de Morales), fue impresa en la misma imprenta de Córdoba, Rafael García Rodríguez, donde se publicó la ed. de $L P E$ que hemos denominado E. Véase, para la imprenta cordobesa, Porro Herrera (2000) y Casas Delgado (2012); para la imprenta de Rafael García, Casas Delgado (2015). Y otra versión del mismo romance, pero con el título de El hechizo de Sevilla (que no hay que confundir con la Comedia famosa. El hechizo de Sevilla, de Ambrosio de Arce, en Valencia, por Joseph de Orga, 1762, aunque el argumento esté relacionado) había sido impresa en Valencia, por Agustín Laborda, lo que me lleva a pensar en la posibilidad de que los ejemplares de la edición A fueran impresos también por Laborda. Véase, para la imprenta de Laborda, el reciente e importante estudio de Gomis (2015).

${ }^{6}$ El frayle fingido es, con toda razón y asombro, llamado por Díaz-Maroto (2009: 116-117 [núm. 119]) «pliego antifeminista». Porque su argumento deriva del del cuento que ya se utilizó para cerrar la versión castellana del Sendebar o Libro de los engaños (Fradejas Lebrero, 1981: 183; Lacarra, 1989: 154). No está estudiado, que conozca, si el romance parte del propio Sendebar o bien de alguna de las versiones italianas posteriores, como propone Ramos (Ramos, 2005: 387). La única edición que conocemos de El frayle fingido se imprime en Córdoba, en dos partes (4+4 hs.), en la Imprenta de Don Luis de Ramos y Coria, sita en la Plazuela de las Cañas, la misma en la que se imprimirá también otro pliego de $L P E$ (para detalles sobre la imprenta popular en la Andalucía del XVIII y XIX, véase Casas Delgado, 2012, 2015).

La asociación no tiene por qué ser casual. Calderón escoge nombres distantes y exóticos, para acentuar la universalidad de su lección: Basilio es 'rey' o 'basileus'; Astolfo es lombardo; Clotaldo, merovingio. Pero, además, Basilio es un rey estrellero, supersticioso, que toma todas las medidas posibles para evitar que el pronóstico se cumpla, pero que consigue justamente todo lo contrario a lo que se ha propuesto.
} 
cervantina que Morales versionó como pliego en verso, a otro igualmente agresor inicial y desencadenante de todo el conflicto que se desarrolla en $L P E$.

En cuanto a la base folclórica con que arranca el argumento de $L P E$ parece que es claramente ATU, 301, The Three Stolen Princesses, aunque en todas las versiones conocidas las tres princesas que son rescatadas por el héroe han sido previamente encerradas en un espacio subterráneo o interior (pozo o cueva), mientras que en $L P E$ lo son en un espacio alto o aéreo (una torre), lo que puede llevar a confundir al inicio del romance con el cuento de Rapunzel, como vamos a comentar. Sin embargo, los motivos básicos son sin la menor duda los que se hilan en el esquema argumental central de ATU 301. El tipo, como señala Uther, combina tres posibles episodios introductorios con una parte principal común. De las tres variantes introductorias, interesa especialmente la primera: «A King banishes his three daughters to the underworld (they are abducted by monsters [H1385.1]). Three brothers (a supernatural hero with his extraordinary companions) go to find the daughters». ${ }^{8}$

No hay otro tipo de cuento folclórico universal con tres hijas rescatadas por tres hermanos. La parte principal del patrón argumental de ATU, 301, si pasamos al núcleo del relato, tras las partes introductorias, es bien reconocible en $L P E$ :

The companions (brothers) come to a well (pit, cave) [F92] and lower the hero (youngest brother) into it [F96]. The hero overcomes monsters (dragons, devils) and rescues (the three) princesses (with the princesses' help, using a weapon, only by his strength, by magic means) [R111.2.1] (The princesses give him presents.) His treacherous companions pull the princesses up but leave the hero below [K1931.2] (cut off the rope [K963], overturn the basket). They force the maidens to name them as their rescues [K1933].

Aunque la bajada al pozo esté diametralmente cambiada como subida a la torre -en el extremo opuesto dentro de un eje lineal de verticalidad que tuviera sus dos puntas polarizadas-, los restantes motivos son, sin embargo, básicamente coincidentes: las tres princesas que han de ser rescatadas, los hermanos, el ascenso/descenso habilidoso del más joven de ellos, la victoria sobre el enemigo encantador (el desencantamiento, en $L P E$ ), el rescate, el presente ofrecido por la(s) princesa(s) (la gargantilla, en $L P E$ ) y, finalmente, la traición de los hermanos que reciben a las princesas, pero dejan al hermano detrás o abajo (arriba, en $L P E$ ), cortando la cuerda y

\footnotetext{
${ }^{8}$ La tercera de las variantes de episodio introductorio, en cambio, sería la que se puede identificar con la historia de Strong John, o Juan el Oso en nuestra tradición hispánica: es la historia del muchacho de extraordinaria fuerza, venida de nacimiento por ser hijo de un oso y una mujer (o un caballo, o lágrimas, en otras tradiciones). El muchacho marcha de casa y encuentra a unos individuos de vigor excepcional o poderes extraordinarios que lo acompañarán en su viaje. Algo que tendría poco o nada que ver con la historia de nuestro protagonista, si no es por la continuación, puesto que el héroe y sus acompañantes —resumo esquemáticamente, a partir de la versión de «La oreja de Lucifer» de Fernán Caballero- 1legan a una sima o pozo en cuyo interior se encuentran unas princesas encantadas, y acampan allí. Por la noche, un enano o demonio golpea sucesivamente a los tres hombres mientras hacen guardia. Pero cuando le toca el turno al héroe, le atiza con su porra y le arranca una oreja. El muchacho fortachón baja al pozo atado a una soga que sostienen sus compañeros y libera a las princesas de sus carceleros (toro, león, serpiente...). Entonces tira de la soga para que los que aguardan arriba las vayan izando, pero cuando es su turno lo abandonan. Gracias a la oreja, que es mágica, consigue comida y bebida y además que los demonios acudan y lo saquen de la sima. Va donde está la princesa, que lo reconoce como su liberador (a veces, gracias a un objeto o prenda que le dejó) y se casa con ella. La tradición hispánica de ATU, 301, se puede seguir en Amores (2002) y Hernández Fernández (2006).
} 
obligando luego a las princesas a reconocerlos y nombrarlos como sus rescatadores. Es, por tanto, el ascenso a la torre el único motivo absolutamente diferente. Así pues, dejando esta disidencia pendiente, sigamos con el argumento reconocible:

The hero returns to the upper world with the help of a spirit, which gives him the ability to fly (a bird to whom he has to feed his own flesh [B322.1]; he ascends on a climbing plant which he himself planted, etc.). The princesses delay their wedding (for a year). On the wedding day, the hero comes to the castle and is imprisoned. But the truth comes to light (the hero is recognized by the princesses when he shows the presents [H80]), and the impostors are punished (banished, killed) [Q262]. The hero marries the youngest princess [L161] and becomes king.

El héroe, en $L P E$, regresará efectivamente al mundo terreno (eso sí, no al superior, en ATU, $301-«$ the upper world»-, sino al inferior), con la ayuda de un caballo volador (en vez de un espíritu que le dé capacidad para volar, como da el denominador común del cuento-tipo 301). La princesa retrasa su boda, en $L P E$, con varias argucias para dilatar la llegada del pretendiente (el torneo y la prueba de la gargantilla). La verdad saldrá finalmente a la luz, cuando el héroe enseñe el presente ofrecido por la princesa, y los impostores sean descubiertos y castigados (perdonados, en LPE). La conclusión es la boda final, por descontado. En resumen, el esquema básico de ATU, 301, The Three Stolen Princesses coincide con las secciones [1], [2] y [3] de LPE.

Hay que insistir en que el motivo de la torre es absolutamente original en $L P E$. Tan original como distintivo o identificador del argumento principal en la tradición textual que aportan algunos pliegos. En la tradición textual y en la gráfica, puesto que la imagen inicial de las hijas del rey encerradas en la torre se destacará en los grabados de la mayor parte de los pliegos sueltos. El de la torre no es un icono habitual en los grabados de pliegos de cordel, que prefieren centrarse en figuras masculinas o femeninas, más fáciles comodines, o en otros objetos vistosos, como las naves. Condicionados por las versiones gráficas y contemporáneas, el motivo de la princesa en la torre, rescatada con la cuerda, nos recuerda el famoso cuento de Rapunzel (ATU, 310, The Maiden in the Tower), con la poderosa imagen emblemática de la trenza-cuerda colgando de manera serpentina de la torre. En el cuento de Rapunzel, poco frecuente, si no inexistente en la tradición hispánica anterior al siglo XX, aparece, en efecto, una muchacha (en $L P E$ serían tres), que se encuentra encerrada en una torre, a causa del odio de su madrastra. Las diferencias, sin embargo, son evidentes: en $L P E$ no se trata de una muchacha encerrada por una bruja, sino de tres hijas condenadas al encierro por un padre cruel; no hay huida de la pareja, sino liberación de las muchachas; y, luego, las tareas difíciles las tendrá que realizar el héroe masculino y no el femenino, como en Rapunzel. En fin, el elemento definitorio de Rapónchigo o Rapunzel es el cabello de la muchacha, anudado como larga trenza, que sirve al príncipe de mágica escalera de ascenso. Y, sin embargo, en el $L P E$ el cabello no se menciona para nada y el príncipe tiene que actuar, de manera mucho más realista, como un herrero, carpintero y alpinista mañoso, auxiliado por su cuerda, martillo y clavos (sin olvidar nunca las provisiones de alimentos, en las que se insiste, ni el transporte en carro), para alcanzar la cumbre de la torre clausurada. ${ }^{9}$

\footnotetext{
${ }^{9}$ Para Rapunzel, relacionada con cuentos hispánicos y filipinos, véase Ashliman (en red, y 2015) y Carruthers (2015).
} 
De hecho, hay un denominador común mucho más relevante, previo a la injusta condena a la(s) muchacha(s), tanto a la torre como al pozo, que tiene que ver con la relación entre el padre y ésta(s) y que demuestra que ambos espacios son equiparables como ámbitos de expulsión y reclusión, en una dinámica de protección enfermiza, o de intento de destrucción o eliminación. El empeño del padre no está motivado, pero parece claro que, precisamente por esa falta de motivación puede estar tratando de reprimir unos deseos incestuosos. En ese sentido, el tema estaría relacionado con el del romance de Delgadina, donde el castigo es igualmente el cruel encierro en torre (aquí sí la torre y no la cueva) de la hija que se opone a los deseos del padre de que sea su «enamorada». Y, sin embargo, al ser tres hijas, y no una, prevalece una idea ancestral del encierro protector y ritual, la segregación protectora de los hijos del rey, que no pueden ver la luz, ni tocar tierra, ni comer comidas normales, o, en el caso de las hijas, también como antesala y preparación para el matrimonio, que testimonian muchos cuentos (Propp, 1974: 49-58).

Lo cierto es que hay también, en la tradición oral, un tipo de esquema narrativo «dinámico y productivo», como lo define Pedrosa (2006: 188), por el que se presenta un conflicto familiar (que puede ser una relación incestuosa exigida por el padre, pero también un desvarío o una muestra de debilidad e incompetencia por parte del varón), que lleva a que la víctima femenina sea recluida en un espacio elevado, vertical, ascendente, que le habrá de conducir a la muerte si no es liberada por alguien de condiciones extraordinarias. ${ }^{10}$

\section{El SEGUNDO COMPONENTE (ATU, 314, GOLDENER): JUAN EL LOCO, JUAN EL TIÑOSO Y EL CABALLO AYUDANTE}

En su Tercera Parte, el romance de $L P E$ planteará un nuevo conflicto. La boda no ha cerrado el problema, sino que lo deja abierto, puesto que la hija del rey ha realizado una boda poco honrosa, a disgusto del padre, que no ha tenido más remedio que aceptarla para cumplir su promesa, y de toda la corte. La reivindicación del héroe ante sus hermanos (el castigo merecido) ha quedado igualmente sin resolver. Y es aquí donde entran los motivos y el esquema de otro cuento, ATU, 314, Goldener (antes The Youth Transformed to a Horse), en cuyo esquema básico el héroe, que ha sido

\footnotetext{
${ }^{10}$ En un relato hindú aportado por Pedrosa (2006), el hermano se empeña en casarse con sus dos hermanas; estas se refugian en una planta de sándalo, que crece y crece. Las dos hermanas van ascendiendo más y más, alejándose del mundo corrupto, mientras sus familiares, desde abajo, las intentan persuadir para que regresen y acepten la voluntad incestuosa del hermano, al igual que los hermanos y madre de Delgadina hacen piña junto al padre e intentan que la muchacha ceda a sus deseos. De hecho, el peligro de incesto producirá, una vez conjurado, un efecto benéfico, como en el Libro de Apolonio - y no unas consecuencias trágicas, como en los casos de Edipo o Delgadina-: el del matrimonio totalmente exógeno, que se supone ha de conducir a la continuidad de un linaje sano y fecundo. El agresor recibirá la punición de la enfermedad (la ceguera) o el ataque bélico, pero la superación de las pruebas de su yerno el héroe -en principio rechazado- permitirá su cura y salvación, en los dos casos respectivos de punición; con lo que se da un proceso de solución de conflictos por medio de la integración (el yerno en palacio), y no de la sustitución (el rey por el yerno). Ese proceso integrador — sutura del conflicto- permitirá que el joven extranjero, desconocido y por tanto no legitimado, obtenga sus credenciales y sea habilitado e integrado plenamente en el orden del núcleo familiar original, después de la recomposición de elementos (finalmente equilibrados sin que se altere a la larga ese orden). Los hermanos oponentes, que evidentemente reproducen el tema bíblico de José y sus hermanos (Génesis, 37), finalmente habrán hecho el papel de parientes falsos o postizos (como las madrastras), hostiles o excesivamente desapegados de la víctima, papel opuesto y complementario al del pariente de sangre (el padre), excesivamente -irracional o pecaminosamente- pegado a la víctima (incestuoso), dos de las formas más típicas de arranque de conflictos en cualquier cuento maravilloso.
} 
prometido al demonio desde su concepción, logra escapar de éste, a veces con la ayuda de un caballo mágico, pero queda marcado con tener el pelo dorado (Goldener), señal delatora de infracción que habrá de ocultar. Ese principio parece que poco tendría que ver con $L P E$, a no ser por la presencia del caballo mágico. Sin embargo, vamos a ver que el atributo del pelo (o su carencia, por ser tiñoso, por enfermedad de tiña) sí va a ser común con $L P E$ y otra versiones vecinas. Además, el argumento-tipo de ATU, 314, sigue así:

The youth covers his Golden hair, pretending to be a scaldhead, and takes service in the king's court as a gardener [K1816.1]. (He says nothing except, «I don't know» [C495.1] Previously Type 532.) But the youngest princess sees him in his true form (as a golden-haired knight who destroys and restores the garden three times) [H75.4]. She falls in love with Goldener [T91.6.4] and chooses him as her husband by throwing a golden apple to him [T55.1]. They marry but the angry king banishes the couple to a shabby lodging [L132, L113.1.0.1].

Recordemos que el héroe de $L P E$, que pasa una transición, de camino al palacio de su amada, haciendo de ganadero, también se cubre la cabeza con piel de cordero para esconder su identidad («de un reciente cordero / de la piel hizo una gorra / a fin de cubrir el pelo»). La princesa, en cambio, pese a no reconocerlo, se enamora de él y le ofrece una manzana dorada como prueba de que lo elige como marido. Se casan, pero el rey está tan descontento por ese enlace que los destierra a un alojamiento indigno, como ocurre en el romance de $L P E$. El «shabby lodging» es un «tosco albergue [...] / donde apartados viviesen / sin ser oídos ni vistos» (III, 15-18). Y también, como en el romance, el tipo ATU, 314 sigue y concluye:

The king demands the help of his sons-in-law. Goldener has only a poor kit and is mocked. With the help of his magic horse he achieves various heroic deeds. He obtains the magic remedy (e.g. milk of a bird, water of life) for the king who had grown blind (cf. Type 551), kills a dragon (cf. Type 300), and defeats a foreign army three times in disguise. He is wounded and is bandaged by the king. Three times he withdraws and is mocked as a fool. Cf. Type 530. Goldener's identity is revealed (e.g. by wounds, brands) and his true status is recognized [H55, H56].

Los motivos principales de la Tercera Parte de $L P E$ (secciones [4] y [5]) coinciden con este argumento-tipo ATU, 314: la ayuda solicitada por el suegro a sus yernos; la obtención de remedios mágicos para la enfermedad del rey (ceguera), en concreto la leche de leona (en vez de la leche de pájaro que se anota) [4b] y la famosa «agua de la vida» del cuento de los Grimm [4a]; la derrota del ejército enemigo [4c]; la revelación y el reconocimiento final [5]. Finalmente, está el hecho de ser despreciado como loco, que asume el protagonista de $L P E$ como «Juanillo el loco» (es una variante, como veremos, del héroe de ATU, 314, que contesta siempre de manera aparentemente estúpida: «I don't know»). Juan se hace el loco, el «fingido loco», al encontrarse con un ganadero (pastor) y vestirse y tocarse la cabeza con piel de cordero: «vestido a lo pastoril / tan tosco como grosero, / pidiendo a algunos limosna / pasaba de pueblo en pueblo». Pero ese Juanillo esconde también su cabellera con el tocado «pastoril». No tiene el pelo dorado, pero no pasa desapercibido el tema del cabello, puesto que la variante principal del tipo ATU, 314, en los cuentos folclóricos hispánicos, es precisamente la representada por Juan el Tiñoso (Joan el Tinyós o En Tinyoset, en la tradición catalana), 
donde se presenta el motivo de taparse los cabellos, argumentando ser tiñoso. La tiña (de tinea, 'gusano'), recordemos, es literalmente 'enfermedad en la piel, específicamente en el cráneo, producida por algún parásito', que suele producir calvicie, como más adelante veremos.

El cuento más difundido y conocido con argumento similar - en especial de la segunda parte o segundo componente de $L P E$ - está en la «Historia que contó el capitán de policía, el onceno», que se narra en las noches 541-542 de Las mil y una noches:

Un sultán tiene un hijo y a la vez que nace un potrillo en sus caballerizas. El sultán predestina una suerte común a ambos y se lo adjudica a su hijo. Cuando el hijo del sultán se hace mayor, muere su madre y el mismo día muere la madre del potrillo. El sultán se casa con otra mujer, una de las esclavas de palacio, y ambos se despreocupan del hijo, quien, sin embargo, se desahoga con su caballo amigo, dándole de comer y beber, y contándole sus penas. La madrastra toma como amante a un médico judío y los encuentros de la pareja adúltera se ven entorpecidos por la presencia del muchacho huérfano de madre, a quien pretenden envenenar con un veneno extraído de la piel de un negro. Pero el caballo lo descubre y se lo cuenta a su amo y amigo (el caballo habla). El muchacho le da la comida que contiene el veneno a un gato, que muere inmediatamente. Los adúlteros saben que el único que ha podido delatalos ha sido el caballo, así que inventan que la mujer del sultán está enferma y requiere como único remedio el corazón de su potro. [2] [Huida del héroe con el caballo mágico] El muchacho, avisado de antemano, pide que le permitan cabalgarlo una última vez. Y, al hacerlo, desaparecen ambos. [3] [El héroe en palacio: reconocimiento y matrimonio, con disconformidad del rey] Llegan a otro reino. El caballo le dice que coja un mechón de sus crines y pedernal y le revela que lo puede invocar quemando alguna de las crines. El muchacho acude al jardinero mayor y le pide trabajo y obtiene el de guiar al buey que da vueltas a la noria de regar. Las siete hijas del rey se pasean por el jardín y al ver al muchacho la hija pequeña les dice a sus hermanas que hasta cuándo van a estar sin maridos, con peligro de agriarse y de que se les revuelva la sangre. La reina se lo dice al rey, quien hace pregonar que todos los jóvenes de la ciudad han de pasar debajo de las ventanas de palacio, para que sus hijas decidan con quién casar. Seis de ellas, todas menos la pequeña, tiran el pañuelo a sendos pretendientes. Obligan al muchacho de la noria a pasar también por allí debajo y la pequeña le arroja el pañuelo. Se casan pero el padre se disgusta y cae enfermo de pena. [4] [El héroe ayuda al rey: superación de prueba] Los médicos le recetan [4b. Leche mágica] leche de osa, recogida en odre de piel de osa virgen. El rey confía en sus seis yernos, heroicos caballeros, pero no en el séptimo, vulgar boyero de noria. Los seis yernos parten en sus buenos caballos en busca de la leche y el jardinero parte en su mulo cojo, aguantando las burlas de todos. Pero a solas quema uno de los pelos del caballo para que le ayude. Los yernos, mientras, regresan pero con leche de osa vieja recogida en odre de piel de osa vieja. Pero el anónimo muchacho trae la leche buena. [5] [Regreso y reivindicación] El rey dice que le concederá a éste la mano de su hija, tras obligarla a divorciarse del boyero, y que le dará la herencia del reino. Cuando va a hacerlo, delante de todos, la hija le hace ver que el muchacho ante quien se ha postrado en agradecimiento es el mismo boyero que aborrecía. Él lo confirma y le dice al rey que, si se arrepiente, está a tiempo de rectificar, pues su hija es todavía virgen. Pero el rey confirma su aceptación. Y - dice el cuento- «al llegar la penetración, el adolescente se portó tan bien, que impidió para siempre a su joven esposa agriarse y tener la sangre revuelta». El muchacho recién casado regresa al reino de su padre, con un ejército numeroso. Su padre había muerto y reinaba su madre, asesorada por su amante el médico judío. Los hizo prender y empalar encima de una hoguera, donde se consumieron. 
No hemos de pensar necesariamente en un cuento milenario. Este cuento, junto con los de su serie, fue incorporado al texto difundido por J. Ch. Mardrus (1898-1904), uno de los principales traductores al francés, adaptadores y divulgadores de Las mil y una noches. ${ }^{11}$ Por tanto, su momento de incorporación al acervo conocido de la recopilación de cuentos árabes es coetáneo al de creación y difusión de los textos que estando examinando, no necesariamente anterior. De otro lado, la adscripción del cuento a ATU, 314, es clara. La primera parte del cuento de Las mil y una noches presenta unos motivos iniciales de agresión inicial al héroe por parte de la pareja adúltera que no se encuentran en las versiones parecidas a la de $L P E$, con una excepción que hemos de ver: el cuento mallorquín de En Mercè-Mercè. ${ }^{12}$ La «Historia que contó el undécimo capitán de policía» incorpora, por su parte, motivos interesantes y aparentemente extraños, como el de la quema de los pelos del caballo cada vez que se le quiere invocar, que también encontraremos en LPE (la quema de la «cerda» del caballo ayudante por tres veces: II, v. 122, 144 y 167) y en En Mercè-Mercè.$^{13}$

En la segunda parte (secciones [2] a [5]), hay grandes similitudes con ATU, 314 y también, por tanto, con la segunda sección de $L P E$ : no hay torneo, pero hay concurso de pretendientes, y hay siete hermanas y siete pretendientes, en vez de tres. Pero se produce el ritual de pasar debajo de la ventana y arrojar un pañuelo como prueba de compromiso (que podrá ser una fruta, pera o manzana, o un ramo de flores, en otras versiones). Se da igualmente matrimonio, con disconformidad del rey; la enfermedad de éste y el viaje del yerno para obtener un remedio maravilloso. También resulta extraño el motivo de la leche de osa, pero se vincula claramente al de la leche de leona, que es motivo folclórico y que encontraremos en $L P E$ y en varias versiones cercanas a $L P E$.

\section{TRES CUENTOS RELACIONADOS CON LAS PRINCESAS ENCANTADAS EN LOS SIGLOS XIX Y $\mathrm{XX}$}

Dejemos por el momento la primera parte de $L P E$, que encajaría bien —de no ser por el elemento distorsionador de la torre, en vez de pozo-, como hemos visto, en el

${ }^{11}$ El cuento, de acuerdo con The Arabian Nights Encyclopedia (Muzolph y Van Leeuwen, 2004: 141), no pertenecería a los manuscritos originales de Las mil y una noches, sino a esa ampliación, para la que Mardrus pudo tomar la versión de Guillaume Spitta-Bey, Contes arabes modernes (1883). Seguimos la ed. de Vernet (1999: 567-569), pero tanto Blasco Ibáñez como Cansinos Assens parten también de la versión ampliada de Mardrus. Aunque ya Washington Irving, que se relacionaba con las elites literarias españolas en el exilio o en España, desde Leandro Fernández de Moratín a Cecilia Böhl de Faber, en sus Tales of the Alhambra, había plasmado la «Leyenda de las tres bellas princesas» (Gurpegui, 1996: 386409), con un tema ligeramente relacionado con el LPE: un rey de Granada, Mohammed 'el Zurdo', que encierra a sus hijas casaderas, sin poder evitar que dos de ellas sean raptadas por sendos enamorados. La leyenda de Irving se ha hecho popular y ambienta la explicación de la historia de una de las torres de La Alhambra.

${ }^{12}$ La madrastra del cuento ATU, 590, The Faithless Mother (previously The Prince and the Arm Bands), que tiene pocas y raras versiones hispánicas (en las tres lenguas románicas), sí que coincide en que la madre inicia una relación con un extraño y, obligada por éste, que teme la fuerza del héroe, finge una enfermedad y envía a su hija a por remedios imposibles para sanarla (entre ellos el agua de la vida, la leche de animal, etc.).

${ }^{13}$ La quema de los pelos se relacionaría, para Eliade (1976), con invocaciones chamánicas al animal mágico para que le transporte al Más Allá. Propp (1974: 285-86), por su parte, vincula los usos para invocar al caballo del eslabón y el pedernal, en ocasiones unidos a los pelos (que hacen de yesca), con la claridad y el vigor especiales necesarios la hora de invocar a los espíritus. En la historia caballeresca de Partinuplés, por ejemplo, el héroe aparece manejándolos como instrumentos imprescindibles. Más modernamente, el uso de las crines de caballo, en la medicina popular, se ha mantenido como remedio para curar verrugas y otras enfermedades de la piel (Ramón Vallejo y González, 2014). 
esquema de ATU, 301, The Three Stolen Princesses. Centrándonos en la segunda parte, existen solamente tres versiones hispánicas, que yo conozca, que se aproximen a su argumento: dos escritas, del siglo XIX; y una oral, que conservamos transcrita. Se trataría, en primer lugar, del cuento de Juan de Ariza, El caballo de siete colores, aparecido en el Semanario Pintoresco Español en tres entregas del año 1848; en segundo lugar, del ya mencionado En Mercè-Mercè, rondalla recopilada en el Aplec de Rondaies Mallorquines (1896) por Antoni Alcover; y, en tercer lugar, del relato versificado (awit) filipino de Juan Tiñoso.

\subsection{El caballo de siete colores de Juan de Ariza (1848)}

Juan de Ariza cuenta con el privilegio de haber sido autor, en plena mitad del siglo XIX, de la primera colección de cuentos populares españoles (Amores, 2001b). Su corta pero original serie, compuesta por cuatro cuentos, llevaba el título de «Cuentos de viejas» y aparecería publicada entre los años 1848 y 1850 en el Semanario Pintoresco Español (1836-1857), la revista fundada por Mesonero Romanos que hacia mediados del siglo XIX mejor iba a contribuir para consolidar el modelo de publicación familiar, de divulgación y de entretenimiento. ${ }^{14}$ La colección de Ariza incluiría los cuentos Perico sin miedo (ATU, 326, The youth who wanted to learn what fear is), que recrearían también Fernán Caballero o Luis Coloma (Amores, 1997: 78-80); El caballo de los siete colores, que examinaremos con más atención; La princesa del bien podrá ser (ATU, 852, Lying contest + ATU, 921, The King and the farmer's son); y, finalmente, El caballito discreto (relacionado con ATU, 330, The clever horse).

El caballo de siete colores - que, como reconoce Amores, se trata «...desde el punto de vista del folclore español, de un caso raro»- salió publicado en tres entregas del año 1848, que corresponden a los núms. 31, pp. 243-244 (30 de julio), 33, pp. 263 264 (13 de agosto) y 34, pp. 278-280 (20 de agosto), y que coinciden con las tres secuencias en las que se divide el relato. ${ }^{15}$ El resumen del cuento es el siguiente:

En «tiempos muy remotos y en un almenado castillo» vive Alfredo, un joven pobre pero de ilustre familia, quien tras quedar huérfano, con apenas quince años, decide abandonar su casa en busca de fortuna. Alfredo es acogido en casa de un gigante y pasa la noche en su castillo sin demostrar miedo ni hacer ninguna pregunta. Como recompensa, el gigante le regala tres objetos mágicos: «una espada de fino acero primorosamente cincelada», «un gorro encarnado y azul» y un caballo «cuya piel reunía los siete colores del iris». [2] [Huida del héroe con el caballo mágico] El caballo «partió al escape con

14 Véase Rubio (1995), Rodríguez (2004) y, en especial, Amores (1997, 2001a, 2001b). Véase también, como trabajo conjunto, Amores y Amores (2014). Ariza cultivó el teatro, la novela histórica, la poesía en romance, el cuento costumbrista (deudor confeso de Mesonero Romanos) y, con más acierto, a decir de Baquero (1992: 67-68), el cuento popular. Ariza, sin el afán científico de los hermanos Grimm, ni el folclórico de Fernán Caballero — quien, como deduce Amores, acabaría reemplazándolo como escritora de cuentos en el Semanario-, declara en su introducción a la colección, en 1848, que se va a limitar a tratar de recordar algunos de los casi mil cuentos - exagera un poco- que de niño le contaba su criada para tratar de convencerle para comer otras tantas tortillas. No hay, por tanto, mayor conciencia de recuperación de temas populares, sino aprovechamiento de materiales que pueden ser alterados a su antojo, como de hecho hará, dándoles forma literaria (Amores, 2001b: 28-29).

${ }^{15}$ Los fascículos del Semanario, donde aparece el cuento, pueden ser consultados en la Biblioteca Virtual Cervantes. Señala Amores: «No conozco ninguna versión oral española parecida, aunque no por ello debe dudarse del carácter tradicional del cuento» (2001b: 34-35). El tema del «caballo de siete colores», en cambio, sí se da en la tradición hispánica, dentro del tipo ATU, 530 (The Princess on the Glass Mountain): Alcover (2006, IV: 276-297), reproducido parcialmente por Camarena-Chevalier (1997: 475-482); y ATU, 531 (The Clever Horse): Camarena-Chevalier (483-487). 
portentosa rapidez» $\mathrm{y}$ «siguió su carrera por espacio de algunas horas»; cuando paran, le advierte - porque el caballo habla - de la ciudad ante la que están, donde habita un rey con tres hijas casaderas, y de los poderes de los objetos que le ha regalado el gigante: quien combate con la espada no pierde jamás y tocando cualquier objeto con su punta queda inmóvil; poniéndose el gorro por el lado azul parecerá un bello y rico caballero, mientras que por el lado rojo parecerá un hombre necio y repugnante; en cuanto al caballo, los siete colores representan las siete veces que puede pedirle favores (ya lo ha empleado una primera vez). Alfredo entra en la ciudad con el gorro puesto por el lado rojo, con apariencia de pobre; paseando, entra en unos jardines, se queda dormido y es despertado y entabla conversación con el jardinero del rey, que le ofrece un trabajo como ayudante.

[3] [El héroe en palacio: victoria en el torneo y matrimonio, con disconformidad del rey] Alfredo conoce a las tres hermosas princesas - la altiva Sara, la glacial Rosa y la dulce y tierna Margarita- y se enamora de la más pequeña, Margarita. Como jardinero le llaman Tiñoso por su aspecto y por el gorro rojo que no abandonaba jamás (como si le tapara la tiña). Sólo le puede manifestar su pasión a la princesa «en el lenguaje de las flores, por medio de fragantes ramos»; aunque a veces se convertía en príncipe - cambiando el lado del tocado del gorro-, produciendo el estupor de Margarita, que lo espía, comprobando confusa cómo de aquel lugar salen dos personajes distintos sin hallar nunca rastro alguno del caballero. El rey convoca un torneo para dirimir quién obtendrá las manos de sus tres bellas hijas. El primer día acuden el duque Alberto y el príncipe Cecilio, pretendiendo a Sara y Rosa. Alfredo decide darse también a conocer bajo el aspecto de caballero, montado en corcel blanco, y derroca al duque y al príncipe, ganando una sortija de brillantes. Cuando llega la noche cambia el lado de su sombrero. La princesa Margarita, que ve en el comportamiento del jardinero algo misterioso, aumenta su estupor al recibir al día siguiente su ramo de pasionarias, sujetos los tallos con la sortija de brillantes entregada al vencedor del torneo.

Al día siguiente se vuelve a presentar el desconocido «aventurero», que consigue seis sortijas de premio y a la mañana siguiente el Tiñoso se presenta a Margarita regalándole un ramo de flores anudado con las cintas de las sortijas. A las insistentes preguntas de la princesa sobre el paladín del torneo y sobre él mismo, el jardinero contesta «Quizás sí, quizás no, quizás sería yo». Esta respuesta trae siempre a la memoria de Margarita las escenas que ha observado en el pabellón del jardín y sospecha más cada día. El último día, el de las cañas, el misterioso caballero se presenta acompañado de doce caballeros de blanco, con sendos caballos de siete colores. Triunfan, naturalmente. Cuando un heraldo le pregunta al aventurero, a instancias del rey, su nombre y procedencia, el caballo le contesta que viene de luengas tierras a ser el heredero de su reino. Acabado el torneo, las princesas deben escoger marido, entregando al elegido cada una de ellas una preciosa rosa de oro. Rosa escoge al duque Alberto, Sara al príncipe Cecilio y Margarita, después de mucho discernir, tras ocho días de indecisiones, llega a la conclusión de que el Tiñoso es un criado del príncipe. Así que el día señalado Margarita entrega la rosa al Tiñoso esperando que éste se la dé al aventurero desconocido. Sin embargo, el día de la ceremonia se presenta el Tiñoso, y el rey, que tiene empeñada su palabra, no tiene más remedio que entregar su hija al jardinero. La boda se celebra y Margarita, que había aceptado al muchacho porque antes le había susurrado algo al oído, es enviada a vivir junto a su marido, en vez de a las suntuosas habitaciones que le correspondían, al rústico pabellón de madera, en lo más oculto del jardín.

[4] [El héroe ayuda al rey: superación de tres pruebas] En la tercera entrega, Margarita vive con Alfredo humildemente. Aunque sabe ya la identidad de su marido no puede darla a conocer pues así se lo ha ordenado él. [4a. Leña de la Selva] Pasados tres meses, una epidemia asola el reino y, para acabar con ella, un sacerdote «acreditado por sus vaticinios», resuelve que se debe conseguir leña de ciprés rojo, que sólo se encuentra en «La selva de los Gigantes», para quemarla durante tres días en la plaza de palacio. Los 
cuñados de Alfredo acuden a instancias del rey, portando regalos para los guardianes gigantes de la selva; pero Alfredo, ayudado por su caballo, se les adelanta. Se enfrentará con el rey de los gigantes, rompiendo como si fuera de cera su gran maza y consiguiendo su pleitesía. El caballo de siete colores le había facilitado como ayudantes a doce labradores, cabalgando doce caballos de labranza, que le ayudarán luego a cargar la leña. Bajo la apariencia de Tiñoso entrega a continuación la leña a Alberto y Cecilio, a cambio de las dos rosas de oro que recibieron de sus novias (pese a parecerles dura exigencia). [4b. Agua mágica] Algo parecido ocurre a continuación con una plaga que lleva el hambre al reino y que dice el sacerdote adivino que sólo acabará si riegan el suelo con agua azul de la fuente de «Los dos mármoles», que brota y se sumerge entre dos mármoles que chocan incesantemente. Alfredo consigue, gracias a su caballo, el agua, que sus cuñados habían intentado recoger infructuosamente, y esta vez la entregará a sus cuñados a cambio de dejarse cortar cada uno la parte superior de una oreja. [4c. Ayuda militar] Finalmente, el reino se ve asediado por un numeroso ejército enemigo. El rey entrega el mando a sus dos yernos, pero es Alfredo quien logra que el caballo mágico le proporcione un ejército brillante y salir victorioso de la batalla. Esta vez el Tiñoso pide a Alberto y a Cecilio que, a cambio del estandarte real, capturado por él al enemigo, marquen sus espaldas con un hierro candente en el que pueda leerse: «Esclavo del Tiñoso».

[5. Regreso y reivindicación] El rey decide poco después partir su reino entre sus dos yernos, Cuando llega el día de la investidura, aparece Margarita, «primorosamente ataviada», para protestar y dar a conocer la verdad. La princesa descubre la falsedad de sus cuñados al entregar a su padre las dos rosas de oro, los dos trozos de orejas cortadas y al descubrir las marcas de sus cuñados. Alfredo es reconocido como el «Aventurero», el caballero desconocido victorioso en las justas, y aclamado en aquel mismo momento para ser el sucesor de la corona. Y acaba el autor el cuento de manera estupenda: «Alfredo me regaló el gorro azul y encarnado, que guardo cuidadosamente para hacer un gran sortilegio contra toda mujer hermosa, que tenga la osadía de poner en duda mi fealdad».

Como señala Amores (2001b: 34-35), el cuento desarrolla la primera secuencia del tipo 590A («La esposa alevosa») -ATU, 590, The Faithless Mother, se relaciona con el cuento de Las mil y una noches-, donde el protagonista recibe tres objetos mágicos (un caballo, una espada y una camisa) por pasar tres noches en un castillo encantado. A continuación, retoma las secuencias últimas del tipo 314 en las que disfrazado de jardinero entra en la corte, la princesa se enamora de él, se casan y los hacen vivir en una pocilga, etc. Observemos que, aunque cambie algunos elementos de esta segunda parte (por ejemplo la leche de leona, como primer remedio para la cura regia, en $L P E$, por leña de la Selva; o las dos peras recibidas a cambio del agua mágica, en LPE, por dos rosas de oro), otros muy significativos se mantienen. Entre ellos, el orden de los remedios (leche de leona / leña de la Selva + agua mágica + ayuda militar) y el que los hermanos consientan, en pago a recibir el primero de los remedios, nada menos que ser desorejados.

\subsection{La rondalla mallorquina «En Mercè-Mercè»}

La rondalla mallorquina de En Mercè-Mercè pertenece al Aplec de rondaies mallorquines d'En Jordi d'es Racó (1896-1935), recopilado por Antoni M. Alcover, una de las colecciones más importantes de cuentos tradicionales o «rondalles» de la tradición catalana y europea. La rondalla, que apareció en el último volumen (vol. XIII) 
del Aplec (1935), ha sido magníficamente editada y explicada, junto con el resto de las de Alcover, por Grimalt y Guiscafrè (2006, IV: 317-351). ${ }^{16}$

El resumen del cuento que Maria Sastre, una mujer del municipio mallorquín de Randa, le contó a mosén Alcover, es el siguiente:

[Coincidencias con el cuento de Las mil y una noches] Un rey y una reina [no se especifican nombres ni localización], por más que lo intentaban, no lograban tener descendencia. El rey, desesperado, estaba a punto de suicidarse en una de sus salidas a cazar al bosque, cuando encuentra una vieja que le da una manzana para que la reina se coma la mitad y dé la otra mitad a su yegua preferida. Al cabo de nueve meses la yegua había parido un potrillo y la reina tiene un niño, al que llaman Bernadet. El rey ha de marchar a la guerra y un turco se hace amigo íntimo de la reina. Como ven que la presencia de Bernadet constituye un peligro, lo intentan matar. Primero, dándole una torta envenenada, aunque el niño es avisado por el caballo amigo, que resulta que puede hablar y le advierte del peligro. Luego, poniendo animales venenosos en la cama, de lo que también le avisa el caballo amigo. Como la pareja adúltera sospecha del caballo consejero y pretenden eliminarlo, el turco le dice a la reina que se haga la enferma y que diga que sólo puede sanar con grasa de caballo. Pero el caballo le avisa a Bernadet y le dice que pida, como último deseo, montarlo y pasearlo tres veces; y que a la tercera, lo azuce bien y saldrán volando hacia otro reino lejano. [2] [Huida del héroe con el caballo mágico] Así se hace. Cuando están bien lejos, el caballo le dice que guarde unas crines de su cola, junto con un eslabón («foguer» o «pedra foguera») y un canutillo de yesca («canonet d'esca»), para que, si se ve apurado, queme una de las crines y diga: «Val Déu i cavallet, ajuda que s'és mester!». El caballo, entonces, acudirá en su ayuda. Pero que se quite el vestido de príncipe que lleva y acuda al rey, vestido como criado, haciéndose el estúpido y contestando sólo «Mercè, mercè» ('Gracias, gracias') a todo lo que se le diga o pregunte. [3] [El héroe en palacio: elección de la princesa y matrimonio, con disconformidad del rey] En la corte, nadie quiere estar con Bernadet y lo dejan de criado del hortelano, que cuida la noria del huerto con una mula, apelándolo burlonamente «Mercè, mercè». El hortelano les hacía un ramillete de flores cada día a cada una de las hijas del rey. Un día se ha de ausentar y las hijas preguntan por su ramillete. Bernadet, apurado, quema una crin con la yesca y pregunta al caballo mágico qué hacer. Este le aconseja que se vista de príncipe, recoja las flores y cante una bonita canción. La hija pequeña del rey lo descubre así, sorprendida por el cambio del criado, y desde ese momento no deja de poner su pensamiento en él, aunque sin decir nada a nadie. A partir del día siguiente, el hortelano le encarga llevar los ramos y que le dé la peseta que recibirá de cada una. Pero siempre la mayor le da nueve sueldos, la otra doce y la menor quince, y él devuelve de menos a más cortesía y reverencias, dependiendo de lo recibido.

El rey quiere casar a las hijas, para lo que manda hacer tres peras de oro, y los pretendientes que las reciban, pasando bajo su ventana, casarán con ellas. Las dos hermanas tiran las peras a dos de los nobles que pasan, pero la pequeña no. Obliga a su padre a que haga otro llamamiento, y que puedan pasar bajo la ventana todos los que quieran, pobres o ricos. Cuando el criado Bernadet pasa, montado en la mula de la noria,

${ }^{16}$ Grimalt y Guiscafrè (2006, IV: 351-352), en el comentario de la rondalla, aluden a lo difícil que es optar entre su clasificación como Aarne-Thompson, 532 o como Aarne-Thompson, 314, citando al propio Thompson, quien reconoce que podría tratarse, no de un tipo independiente, sino de una variante de la historia del jardinero (Aarne-Thompson, 314, Gardener). La misma clasificación de Aa-Th, 532 le dan Camarena y Chevalier (1995: 488-502), quienes reproducen parcialmente la versión de Alcover y sólo logran aportar otras dos versiones del tipo (una dominicana, más una portuguesa). De hecho, A-Th, 532 queda integrado por Uther como ATU, 314. Y, en efecto, el Rondcat (Cercador de la Rondalla Catalana) adscribe la rondalla claramente al tipo 314. 
le arroja la pera, que él recoge. El rey, enfadado por la elección, le da la llave de una habitación del huerto para que vaya, si quiere estar con su elegido. [4] [El héroe ayuda al rey: superación de pruebas] [4c. Ayuda militar (1)] Mientras, sus enemigos mueven una guerra contra él y tiene que acudir a combatir, acompañado de sus yernos. El hortelano le aconseja a Bernadet que acuda a la guerra a ayudar. Y allí va él, montado en su mula. Una vez en la guerra, enciende otra crin y pide al caballo mágico un caballo negro, para él, más un ejército de caballos blancos con sus jinetes, soldados que no se arredren. Cuando entran a luchar en la batalla, que ya perdían el rey y sus yernos, hacen que la victoria se incline de su lado. Pero no se descubre al rey, regresa adonde había dejado su mula, desaparece por encanto el ejército mágico, y vuelve a su huerto y a su noria. [4c. Ayuda militar (2)] Al cabo del tiempo, vuelve a desencadenarse otra guerra, de nuevo va perdiéndola el rey y de nuevo el hortelano pide a Bernadet que acuda; allí se repite la petición al caballo mágico, esta vez de un ejército - cambiando colores- de caballos negros, y uno blanco para él. De nuevo, hacen que el rey venza la batalla y la guerra. Al retirarse, sin descubrir quién es, el rey le lanza una flecha que se le clava en el muslo. Pero él regresa a su noria. [4a. Agua mágica] Cuando pasa una temporada, el rey cae enfermo de los ojos y los mejores médicos le recetan que sólo puede evitar la ceguera lavándolos con agua de la Bella Fuente. Los yernos van en su busca, aunque no saben dónde está. Y el hortelano le dice que vaya él también, si quiere casar con la hija del rey. A los siete días de camino, como no sabe dónde está la fuente, quema otra crin para pedir consejo al caballo. Éste le avisa de que tirando tierra al aire, habrá de ir hacia donde la lleve el viento; encontrará un gigante guardando la fuente: si tiene los ojos cerrados, está despierto; si los tiene abiertos, es que duerme. Ha de aprovechar que los tiene abiertos para pasar y tomar el agua. El gigante no lo puede alcanzar. De regreso, se atasca la mula en un barrizal. Como pasan los yernos del rey, de regreso de su búsqueda infructuosa del agua curativa, les pide ayuda. Ellos le preguntan qué lleva en la botella. Y cuando les dice que agua la Bella Fuente para curar a su padre de la vista, le ofrecen lo que sea, con tal de obtenerla. Él acepta, finalmente, darles el agua mágica, pero a cambio de las dos peras de oro recibidas de las princesas para casar con ellas. Cuando regresan, el agua cura la incipiente ceguera del rey y nadie sospecha de que no hayan sido sus yernos los salvadores. [4b. Leche de leona] Pero el rey vuelve a caer enfermo, de debilidad y melancolía extremas. Los médicos le recetan esta vez leche de leona. Los yernos vuelven a partir en su busca. Y Bernadet, a quien se lo vuelve a decir el hortelano, igualmente. Vuelve a invocar al caballo mágico y éste le indica dónde está el bosque en el que encontrará a la leona dando leche a sus cachorros, y le dice que le ayudará, adormeciendo a la leona. Logra llenar una botella de leche de la leona y, de regreso, vuelve a ocurrir lo mismo que la vez anterior: se le atasca la mula y pide ayuda a los dos yernos del rey (que no lo reconocen, porque ha comprado dos sacos de carbón y creen que es un carbonero). De nuevo descubren la leche, le preguntan y él les confiesa inocentemente que es de una leona. Le piden lo que sea a cambio de la leche. Y él, siguiendo el consejo del caballo protector, les dice que habrán de ser marcados a fuego con una herradura de su mula en las ancas o nalgas. No tienen más remedio que aceptar ese trueque y él, con su yesca y el carbón comprado, enciende un fuego en el que pondrá al rojo vivo la herradura y los marcará. [5] [Regreso y reivindicación] Cuando regresa Bernadet vuelve al anonimato, pero va a curarse la flecha que le lanzó el rey tras la batalla y, como inesperadamente sale la punta de la herida, lanza una exclamación, y la princesa, siempre pendiente, la escucha y lo descubre. Él la persuade para mantener el secreto y decirle a su padre que convoque una reunión de todos para traspasar la corona a quien definitivamente la ha ganado. En la reunión, el rey pregunta quién ganó la primera batalla y Bernadet, vestido ya de príncipe, contesta que él; quién ganó la segunda, e igual, enseñando como prueba la flecha; quién trajo el agua milagrosa, y él dice la verdad, mostrando como prueba las peras de oro; y, finalmente, quién la leche de leona, y él sigue reivindicando su protagonismo, haciendo que se vean las marcas de herradura. Así que el rey no tiene dudas al cederle su corona. 
Bernadet pide entonces que no salga nadie, mientras cuenta su historia. Al hablar de su padre, engañado por su madre, éste lo reconoce y abraza. La madre cae desmayada y revienta. Y el turco es castigado a ser descuartizado por cuatro caballos, que lo despedazan. A los siete días tienen lugar las bodas y Bernadet hereda dos coronas: la de su suegro y la de su padre.

Como indican los editores, la rondalla contiene similitudes llamativas, en su primera parte, con la «Historia del undécimo policía» de Las mil y una noches, que hemos introducido antes: nacimiento simultáneo del héroe y del que será su caballo ayudante, adulterio de la reina, envenenamiento frustrado del caballo, intento de matar al caballo delator fingiendo enfermedad de la reina, huida del héroe con su caballo parlante, etc. La respuesta única del héroe, llegado a palacio, «Mercè-Mercè», que da título a la «rondalla», coincide con el elemento que singularizaba el tipo 532 (I don't know; adscrito luego a ATU, 314). A partir del disfraz de jardinero que permite al héroe mantenerse de incógnito, consiste en una fingida incapacidad para hablar, o articular otra cosa que no sea un «No lo sé», un 'Gracias, gracias' («Mercè, Mercè»), como aquí, o, como hemos visto en el cuento de Juan de Ariza, "Quizás sí, quizás no, quizás sería yo». Son maneras de enfatizar el descenso social que se ve obligado a efectuar el héroe para conseguir sus objetivos. Haciéndolo, además de pobre, estúpido, y sumando al disfraz la incapacidad verbal (y el retraso mental de la que es síntoma) se acrecienta el rechazo del excluido.

Grimalt y Guiscafrè (2006, IV: 317-318) relacionan el tema general de la rondalla con el de la historia caballeresca de Roberto el Diablo, quien es obligado por un ermitaño a expiar sus maldades regresando a la corte y haciéndose pasar por loco y mudo. En el palacio del emperador de Roma, le ayudará de incógnito a sofocar una rebelión militar y un caballero le tira una lanza, cuya punta queda clavada en su muslo, lo que servirá para identificarlo luego. ${ }^{17}$ Este motivo, en efecto, y otros, como el de la mudez simulada, coinciden en los dos relatos, aunque el de Roberto el Diablo es básicamente edificante. Hay similitudes palmarias con $L P E$ y con El caballo de siete colores de Ariza, en fin, a la hora de exponer bajo la Ley del Tres los remedios para que el rey se recupere. Mercè-Mercè presenta exactamente los mismos (ayuda militar, agua mágica y leche de leona), sólo que cambia el orden y desdobla la ayuda militar. Pero concuerdan también en los motivos de los dones que entregan los hermanos alevosos a cambio (las dos peras y dejarse marcar con el estigma de la esclavitud), aunque añaden alguno nuevo, como el de la punta de flecha que servirá también de reconocimiento.

\subsection{Las versiones filipinas de «Juan y Clotilde» y «Juan Tiñoso»}

El comentario de los siguientes textos requiere una explicación previa. Nos adentramos no sólo en un mundo geográficamente nuevo y muy distante (el archipiélago de las islas Filipinas), sino en un territorio lingüísticamente diferenciado, no ya del castellano (como en la rondalla catalana), sino de las variantes románicas. Pese a que existe, antigua y viva, toda una rica literatura española procedente de los tiempos de la colonia, no nos vamos a referir a textos filipinos en castellano, sino a cuentos o narraciones versificadas recogidos o trasmitidos en tagalo $\mathrm{u}$ otras lenguas

\footnotetext{
${ }^{17}$ Curiosamente, una traducción de Roberto el Diablo, con una amplísima tradición impresa como relato popular en castellano, desde 1509, fue publicada por el mismo Semanario Pintoresco Español que publicaría en 1848 El caballo de siete colores de Ariza, pero diez años antes: en los números 109, 110, correspondientes al 29 de abril (pp. 544-545) y 6 de mayo de 1838 (pp. 555-556).
} 
indígenas, aunque, eso sí, claramente dependientes — variaciones o adaptaciones- de otros precedentes hispánicos.

Aunque no se hayan señalado antes, a la vista del argumento de un cuento como el de Juan y Clotilde, que recoge Fansler y cuya sinopsis presentamos a continuación, me parece productivo proponer las huellas del romance de LPE, a partir de la difusión del pliego suelto en Filipinas, desde mediados del siglo XIX. ${ }^{18}$ No sería, desde luego, el único caso, sino que esta vinculación entraría en el contexto de toda una serie de influencias recíprocas, a lo largo de todo el siglo XIX y parte del siglo XX, entre la literatura popular española difundida en pliegos sueltos y algunas narraciones orales filipinas, muchas veces plasmadas a su vez en pliegos escritos en tagalo o en alguna otra lengua isleña. Señala Fansler (1921: 355-359) que el cuento de Juan y Clotilde, en concreto, fue contado por Vicente Hilario, un tagalo que declaró haber escuchado la historia de un anciano que vivía en Batangas. Para el folclorista, no cabía duda de que era un cuento - como tantos otros de su colección- de origen occidental, en concreto español o portugués. El argumento es el siguiente (me limito a volver a traducir, apenas retocada, la versión en inglés de Fansler):

[Las causas del encierro de la princesa] En tiempos remotos y en tierras lejanas vivía un poderoso rey conocido en todo el mundo, cuyo nombre era Ludovico y cuyo poder se había duplicado gracias a su relación con un viejo mago, con el que había establecido estrechos vínculos de amistad. Ludovico tenía una hermosísima hija llamada Clotilde, por la que el mago, desde su llegada al palacio, se había sentido apasionadamente enamorado, aunque tanto su extrema vejez como su comportamiento altivo eran claros impedimentos en sus intentos de acercamiento. Cada vez que trataba de mostrarle su amor, ella se volvía a un lado, y prefería escuchar los emocionantes cuentos contados por algún juglar errante. El mago finalmente sucumbió al peso de la vejez, hundido por las constantes desilusiones. Al morir, le dejó al rey tres caballos alados encantados y a la princesa, dos collares mágicos de exactamente la misma apariencia, obra inimitable hecha a mano y de valor incalculable. Pero no dejó de vengarse de la causa de su muerte. Antes de expirar, encerró a Clotilde y los tres caballos mágicos en una alta torre, inaccesible para cualquier ser humano. Ella tendría que permanecer en esta prisión encantada hasta que alguien lograra liberarla.

[1] [Princesa liberada y hermano traicionado] Naturalmente, el rey Ludovico quería ver a su hija antes de la hora de su muerte, que también se acercaba veloz. Ofreció entonces grandes sumas de dinero, junto con su corona y la mano de Clotilde, a cualquiera que pudiera sacarla de la torre. Cientos de príncipes lo intentaron, pero en vano. Las paredes de piedra de la torre eran de una altura tal que incluso muy pocas aves podían volar por encima. Pero un libertador surgió de la oscuridad sobresaliendo entre todos. Se trataba de un campesino sin educación, pero perseverante llamado Juan. Estaba dotado de elegante disposición, fuerza hercúlea, buen corazón e ingenio sin igual. Sus dos hermanos mayores, más instruidos, habían tratado de escalar las paredes de la torre, pero no les fue mejor que a los demás. Finalmente, llegó el turno de Juan. Sus padres y sus

${ }^{18}$ La recopilación de los Filipino Popular Tales de Fansler (1921) constituye, para los historiadores de la literatura del país del Pacífico, una colección pionera en la recuperación fijación de tradición oral del archipiélago. Fansler, formado como historiador y folclorista, tradujo y, por tanto, reescribió necesariamente en inglés más de cincuenta cuentos (en su Introducción justifica convincentemente la elección de esa lengua), casi siempre a partir de los testimonios de informantes, de quienes ofrece en muchos casos, como buen folclorista, nombre y datos. Y lo hizo, además, estableciendo nexos con otros de otras tradiciones - estaba al tanto de los avances en los estudios y catalogación de cuentos universales- y ofreciendo valiosos comentarios. 
hermanos mayores le aconsejaron que no fuera, porque ¿qué iba a poder hacer alguien no preparado como él? Pero Juan, con la esperanza de liberar a la princesa, no prestó atención a sus consejos. Tomó tantos clavos grandes como pudo encontrar, una cuerda muy larga y un fuerte martillo. Como vivía en una ciudad varias millas de distancia de la capital tuvo que hacer el viaje a caballo.

Un día Juan salió con todo su equipo. En el camino se encontró con su segundo hermano, decepcionado de volver después de un intento vano. El hermano mayor intentó de todas las maneras que pudo desviar Juan de su propósito. De hecho, los padres de Juan, movidos en parte por un sentimiento de vergüenza de que fallara y en parte por un profundo odio, habían envenenado su comida sin su conocimiento. Cuando sintió hambre, sospechó de alguna mala intención, por lo que antes de comer dio a su caballo algunas de sus provisiones. El pobre animal murió en el camino en medio de terribles sufrimientos y Juan se vio obligado a terminar el viaje a pie. Cuando llegó al pie de la torre, clavó un clavo en el muro. Luego ató un extremo de la cuerda a este pico. De esta manera pudo fabricar una escalera completa de los clavos y la cuerda que llegara hasta lo alto de la torre. Allí vio a Clotilde, que se encontró con él con los ojos inundados de lágrimas. Como recompensa por sus servicios, ella le dio uno de los collares mágicos. Mientras susurraban palabras de amor, se escuchó un ruido ensordecedor en la base de la torre.

— ¡Corre a la escalera! —exclamó Clotilde—. Uno de los amigos diabólicos del mago te va a matar.

Pero, jay!, una inmisericorde mano había extraído los clavos; y esta persona no era otra que el segundo hermano de Juan.

-Estoy perdido- dijo Juan.

- Monta uno de los caballos alados que hay en la habitación de al lado — dijo Clotilde. [2] [Huida del héroe con el caballo mágico] Así que Juan montó en uno de los animales sin saber adónde ir. El caballo voló desde la torre con tal velocidad que Juan tuvo que cerrar los ojos. Se quedó sin respiración. En pocos segundos, sin embargo, había aterrizado en un país totalmente extraño a sus ojos. [Allí tuvo que estar mucho tiempo, recuperándose de su desgracia.]

[3] [El héroe en palacio: reconocimiento y matrimonio, con disconformidad del rey] Después de largos años de lucha contra la pobreza y el hambre, finalmente Juan se sentía capaz de regresar a su país de origen. Se fue a vivir a un lugar justo a las afueras de los muros de la capital. Un viejo rico llamado Telesforo lo contrató para trabajar en su granja. El excelente servicio y la conducta irreprochable de Juan se ganaron la buena voluntad de su amo, que lo adoptó como hijo.

Casi al mismo tiempo el rey Ludovico hizo entrega de proclamas declarando que cualquiera que pudiera presentar un collar que coincidiera exactamente con el de su hija, podría ser su yerno. Miles lo intentaron, pero en vano. Incluso los forjadores más diestros y experimentados estaban muy preocupados en sus intentos de producir una falsificación exacta. Cuando la noticia de las proclamaciones reales llegó a Juan, decidió probar. Un día se hizo pasar por enfermo, y le pidió a Telesforo ir al palacio para obtener collar de Clotilde. El anciano, que estaba preparado para servir a su hijo adoptivo, fue esa misma tarde y pidió prestado el collar, para que pudiera tratar de copiarlo. Cuando regresó con el artículo mágico, Juan saltó de la cama y besó a su padre. Después de la cena, Juan fue a su habitación y se encerró en ella. Luego se sacó del bolsillo del collar que Clotilde le había dado en la torre, y lo comparó cuidadosamente con el prestado. Cuando vio que no diferían en ningún aspecto, tomó un trozo de hierro y estuvo golpeando hasta la medianoche.

A la mañana siguiente Juan envolvió los dos collares mágicos en un pañuelo de seda, y le dijo al anciano que los llevara al rey.

— ¡Gracias a Dios! —exclamó Clotilde cuando su padre el rey desenvolvió los collares-, mi amante está aquí otra vez. 
—Este collar — dijo ella, tocando el que había dado a Juan — no es una falsificación, porque está escrito en el libro del mago del arte negro que ningún ser humano será capaz de imitar ninguno de los collares mágicos.

— ¿Dónde está el dueño de este collar, anciano? — dijo, dirigiéndose a Telesforo.

-Está en casa — dijo Telesforo, con una reverencia.

- Id y traedlo a palacio - dijo Clotilde.

Al cabo de un cuarto de hora llegó Juan. Después de rendir el debido saludo de respeto al rey, Juan abrazó amorosamente a Clotilde. Se casaron esa misma tarde, y las fiestas continuaron durante nueve días y nueve noches. Juan fue proclamado príncipe heredero, y a la muerte del rey Ludovico le sucedió en el trono. El rey Juan y la reina Clotilde vivieron hasta su vejez en paz y próspera felicidad.

El argumento abarca solamente la primera y segunda partes del de $L P E$, es decir las secciones [1] a [3], pero no las secciones [4] y [5]. Hay faltas de coherencia debido a ese cierre precipitado, en especial porque el tema de los hermanos alevosos queda sin sentido, al no darse una reivindicación del hermano menor. No cabe duda de que el cuento está simplificado. Pero, teniendo en cuenta las patentes semejanzas argumentales, en detalles como el de la escalada a la torre, el objeto de reconocimiento (la gargantilla o collar), etc., no creo que quepa duda de que, o bien el cuento de Juan y Clotilde fue versionado a partir de algunos de los pliegos de $L P E$, o bien ambas versiones proceden de un texto común. La primera alternativa no es difícil de aceptar, si tomamos en consideración que se dieron otro tipo de influencias de más pliegos sueltos (o del mismo pliego de $L P E$ ) en otras versiones de cuentos o relatos versificados filipinos. En cuanto a la segunda, en cambio, no podemos aportar ningún texto anterior que presente un común denominador. El argumento de El caballo de siete colores, de Ariza, que pudo haber llegado a Filipinas difundido por el Semanario Pintoresco Español, o a través de un resumen oral, está muchísimo más alejado de Juan y Clotilde que el argumento de LPE. Pensemos que ni el cuento de Ariza ni En Mercè-Mercè aportan el motivo básico de la princesa rescatada de la torre, que es esencial tanto en $L P E$ como en el cuento filipino. Creo que hay que concluir sin mayores dudas que el cuento de Juan y Clotilde procede de uno de los pliegos de $L P E$ o de alguna variante o traducción derivada suya. Eso sí, el cuento tagalo tendría que partir de alguna de las versiones posteriores al Romancero general de Durán -o proceder directamente del Romancero general de Durán-, puesto que está ausente todo el episodio del torneo caballeresco, donde el héroe recurre hasta tres veces a las crines del caballo mágico para que le ayude, como está ausente en las versiones de Durán y posteriores (las de los textos $\mathrm{G}$ o $\mathrm{H}$ del romance en dos partes).

Fansler (1921: 358-359), de hecho, anota la relación argumental con $L P E$, aunque no reconoce una filiación que para nosotros resultaría más que plausible. ${ }^{19}$ Nos ofrece, además, un apoyo importante en nuestra argumentación, al señalar el parecido de la Segunda Parte de $L P E$ (el romance núm. 1264, en la edición de Durán, que es la que le sirve de referencia en su estudio) con otro texto también tagalo, Juan Tiñoso, el que vamos a ver a continuación: «There is a sequel to this ballad, No. 1264, which has a

19 Fansler anota: «This Tagalog Märchen appears to be closely related to an eighteenth-century Spanish ballad by Alonso de Morales. The ballad is No. 1263 in the Romancero General, and is entitled «Las Princesas Encantadas, y Deslealtad de Hermanos». Acota, sin embargo: «Although in general outline the two stories are very close to each other, there are some significant differences. [...]-The differences noticeable between our Märchen and the ballad may be due to a tradition somewhat divergent from that on which Alonso de Morales's poem is based» (1921: 359). 
close resemblance to the Tagalog «Juan Tiñoso», already summarized in the notes to No. 36 [id est, "Pedro and the Witch"]».

Pero hay que aclarar que Juan Tiñoso no es un cuento de tradición oral, como Juan y Clotilde, sino un relato versificado. Las novelas versificadas («metrical romances») en tagalo, llamadas korido o «corrido» (en octosílabos) o awit (en dodecasílabos), son narraciones que giran en torno a temas heroico-caballerescos, religiosos, legendarios o folclóricos. ${ }^{20} \mathrm{El}$ awit y el korido, los géneros literarios más populares en la época de colonización, están poderosamente influidos por la literatura extranjera; sus exóticos temas — que pueden parecer tan pueriles como absurda y deliciosamente fantásticos- no tenían nada que ver con la historia indígena, sino con reyes, caballeros, duques y embajadores, luchando contra turcos y árabes. ${ }^{21}$

La materia oral no podía cuajar en castellano, dada la escasa extensión de la lengua en Filipinas, pero pasaría a explicarse, traducirse o adaptarse a la lengua vernácula, y de la oralidad pasaría a la experimentación literaria. ${ }^{22}$ Sin embargo, solamente a través de la presencia en territorio filipino de pliegos sueltos importados, pienso, se puede explicar la profusión de materia carolingia y novelesca afín a la hispánica. El fenómeno de importación trasatlántica que constatamos con los pliegos portugueses importados, primero, e impresos luego, en Brasil (en otro sentido, los llevados a las Canarias), pudo darse de modo semejante, salvando todas las peculiaridades, en Filipinas. Tras cada awit o korido con historias de origen peninsular parece estar un pliego, o parte o conjunto de pliegos, si bien comprobarlo sería un trabajo que excede los objetivos de este artículo.

\footnotetext{
${ }^{20}$ Han sido bien definidas y estudiadas por Eugenio (1987), en su libro Philippine Metrical Romances, que es el estudio de referencia. Véase también Mojares (1983) y Lumbera (1986), así como los trabajos fundamentales de Donoso Jiménez $(2007,2011$, 2012, 2015), principal conocedor de esta literatura en España.

${ }^{21}$ Sus esquemas fijos (cuartetos monorrimos asonantes, entre unos centenares y hasta miles de versos) pasaron a la oralidad. Trinidad H. Pardo de Tavera los define como: «stories in verse about historic events, falsified and fanciful, and love tragedies full of wonderful events mixed with divine prodigy and diabolical magic - all lengthy, exaggerated, puerile, and absurd in the extreme. Not one of the characters is native. All are Turks, Arabs, knight-errant, ambassadors, dukes, warriors in armor, provided with magic arms and with balsams like the famous one of Fierabras, good Castilians and bad strangers. All the characters are at variance with Philippine life; for they are only semblances of the real and true beings of unknown lands and of prodigious races» (apud. Eugenio, 1987: 14-15).

22 Donoso $(2007,2011)$ explica perfectamente cómo las Filipinas crearon una novelística propia (él la denomina «romancero», utilizando un término que a mi juicio puede llevar a equívocos), a partir de elementos heterogéneos con matriz hispánica. Las estructuras de la poesía indígena se acomodaron a la nueva tradición de versos en métrica regular. El mismo Donoso (2015: 184-185) insiste en la relevancia exclusiva de la tradición oral. En su opinión, los romances (o narraciones) serían trasmitidos por soldados, frailes y mujeres españolas, sobre todo éstas, que los trasladarían a sus hijos y familiares.

${ }^{23}$ La escritura de narraciones versificadas (romances) se inicia con José de la Cruz (1746-1829) y será consolidada durante el siglo siguiente con Francisco Baltazar, conocido como «Balagtás» (1788-1862). La mayoría de poemas, sin embargo, no tienen firma. Se pueden distinguir distintos ciclos: el carolingio, el artúrico, el de historias españolas y portuguesas, el relacionado con libros de caballerías castellanos, los cuentos didácticos orientales, el ciclo de Constance, las novelas clásicas, las vidas de santos y los cuentos misceláneos. Así, en el ciclo carolingio, encontramos los poemas o narraciones versificadas de Clodoveo y Clotilde, Los Doce Pares de Francia, Baldovinos, Irlos o El conde Dirlos; en el Ciclo artúrico, Tablante de Ricamonte. En el Ciclo de historias hispánicas, destaca, entre otras, la historia de Rodrigo Díaz, que se transforma en la de Rodrigo de Villas, con pormenores nuevos, sin arraigo tradicional — como ya reconocía Menéndez Pidal-, pero con nombres, motivos y ambiente de puro romancero. Pero también tenemos las historias de Bernardo Carpio, los Siete Infantes de Lara, Almanzor, Inés de Castro (Inés de Portugal) o Gonzalo de Córdoba, el Gran Capitán. Entre los libros de caballerías, Oliveros y Artós
} 
Tenemos la fortuna de contar con una buena traducción al catalán de Juan Tiñoso, que trata de mantener la estructura estrófica del original, a cargo de Donoso (2015), acompañada además de estudio. El argumento, que trato de resumir a partir de esta traducción, sería el siguiente:

[1] [Expulsión del héroe] En el reino de Hungría vive el rey Diego, que tiene cuatro hijas: Juana, Laura, Flora y Flocerpida. Mientras, en el reino de Valencia gobiernan los reyes Artos y Blanca, padres de un niño llamado Juan Tiñoso. Juan, al escuchar los llantos espantosos de un gigante recluido en prisión, se apiada de él y lo pone en libertad. Como recompensa, el gigante le ofrece un pañuelo mágico, que tiene la propiedad de controlar las bestias. Pero cuando el rey Artos se entera de esta acción de su hijo, se enfurece tanto que lo expulsa de casa y ha de marchar exiliado de Valencia. Se refugia entonces en los bosques, donde domina a las bestias, viviendo en cuevas, pero con la intención de marchar al lado de su amada Flocerpida (arrebatado amor de oídas).

[3] [El héroe en palacio: reconocimiento y matrimonio, con disconformidad del rey] Con este propósito tomará la figura de un viejo leproso, viajará al reino de Hungría y se alojará en una casa donde lo atienden por caridad. La princesa acude a visitarlo allí, sin conocer su identidad, demostrando tener un corazón compasivo; pero no descubre que se trata de un joven príncipe hasta que un día lo contempla bañándose, sin disfraz, y desde ese instante queda enamorada de él. El rey Diego, que está enfermo, quiere casar a sus cuatro hijas, así que organiza una justa en que quien sea capaz de alcanzar unas granadas doradas, será elegido para tomar la mano de las hijas. Se celebran las justas, pero Flocerpida no entrega ni arroja la granada a nadie, lo que enoja mucho el rey. Finalmente, se repite el evento y Flocerpida lanza la fruta al viejo leproso; éste la coge y se produce una gran desolación entre la gente porque no aprueban que una princesa tan hermosa tenga que casar con un viejo leproso. Sin embargo, la boda tiene lugar, aunque los esposos son desterrados por la humillación que esto causa al reino.

[4] [El héroe ayuda al rey: superación de pruebas] [4c. Leche de leona] El rey contrae una enfermedad y los médicos le recetan leche de leona para curarla. Será en este momento cuando se ponga en evidencia la condición miserable de los tres príncipes que han casado con las otras tres hijas del rey. Estos tres príncipes humillan al viejo leproso y se lo llevan a las montañas para que sea pasto de las bestias y ellos, mientras tanto, puedan obtener la leche. Pero son tan cobardes que nada más ver a los leones y tigres se escapan subiendo a los árboles. Entonces el leproso se transforma en Juan Tiñoso, gracias a su pañuelo mágico adquiere la armadura y el caballo de un príncipe, acude velozmente y se anticipa a sus hermanos, cogiendo la leche de la leona. Cuando llegan los tres príncipes, sus cuñados, y se la piden, le dice que les dará la leche, siempre que acepten ser esclavos suyos, dejándose marcar en la espalda con una inscripción que lo acredite. Así se hace y quedan marcados con hierro candente. El rey se cura. [4c] [Ayuda militar] Pero entonces el embajador moro llega al palacio con una embajada y se declara la guerra. Vuelve a ponerse de manifiesto la cobardía de los príncipes y la caballerosidad de Juan Tiñoso. Terminada la guerra, se celebran grandes fiestas. [5] [Regreso y reivindicación] Juan Tiñoso finalmente revela la verdad a Flocerpida, que permanecía sin poder acceder a su amado príncipe vestido de leproso, y ambos finalmente pueden estar juntos. Juan

(Arturo), Adriana y Partinoples, Clamades y Clarmonda, la novelita que inspiró el episodio quijotesco de Clavileño («El caballo de madera», Kabayong Tabla), Roberto el Diablo, Flores y Blancaflor, o La donzella Teodor. Entre las novelas italianas, Griselda y Romeo y Julieta. En el ciclo de Constance, Florence y la Emperatriz de Alemania. Y entre los cuentos misceláneos, destaca Florante y Laura, de Francisco Baltazar, considerada la principal obra del género, remotamente relacionada con el Olivante de Laura castellano, así como Palmerín, Segismundo y Policena. En fin, hasta veinte narraciones métricas más, estudiadas por Mojares (1983) y Eugenio (1987), entre otros. Para la literatura de cordel brasileña, en relación con la medieval hispánica, véase Chozas (2015). 
Tiñoso, ahora ya vestido como un príncipe, se presenta de improviso a las celebraciones y exige la propiedad de los tres príncipes cobardes, como esclavos suyos que son. Éstos no pueden negar la evidencia de las marcas que tienen en la piel. Se produce una gran conmoción en palacio. Artos cede el trono a su hijo Juan Tiñoso que, junto con su estimada Flocerpida, es proclamado rey de Valencia.

\section{VERSOS DE LOS PLIEGOS DE LAS PRINCESAS ENCANTADAS RECITADOS EN LA GOMERA}

El romance de $L P E$ ha tenido, además de las posibles relaciones con los textos examinados, una insólita pervivencia oral, constatada al menos en el archipiélago canario, en la isla de La Gomera. El infatigable trabajo de Maximiano Trapero en torno a la pervivencia oral de romances en las Canarias, culmina en el caso de La Gomera con la edición revisada del Romancero General de la isla, donde encontramos transcritos dos de los tres únicos testimonios orales conservados en las Islas - y los únicos, que sepamos, en el ámbito hispánico- del romance de LPE (Trapero, 2000: 398-399). ${ }^{24}$ El primero de ellos es un recitado muy extenso de Ángel Cruz Clemente, de 54 años, de Hermigua, recogido por Maximiano Trapero y Helena Hernández el 23 de julio de 1983, y corresponde a la primera parte del romance. El informante acaba su recitado de 110 versos (que dan cabal resumen de los 330 versos de la primera parte de LPE), excusándose de que, aunque el romance sigue, él no recuerda de la segunda parte más que alguna palabra del primer verso. (La grabación del recitado se puede consultar también en red.)

Para comprobar la literalidad de lo memorizado, transcribamos, por ejemplo, los primeros versos de LPE: «Cuando el Católico Rey / [dos vv. suprimidos] / lanzó la secta Morisca [cuatro vv. suprimidos] / de los primeros cristianos / que hubo cuando la conquista [seis versos suprimidos]. / Era su nombre Clotaldo, / era casado y tenía / de su feliz matrimonio / la belleza de tres hijas [dos vv. suprimidos]. En la versión de La Gomera resultan: «Cuando el Católico Rey / la sola seta morisca / de los primeros cristianos / que hubo cuando la conquista. / Su nombre dera Grotaldo, / era casado y tenía / de su feliz matrimonio / la belleza de tres hijas».

Cotejada con el texto del pliego la versión de Ángel Cruz recoge con meritoria fidelidad el texto del contenido argumental básico, haciendo muy ágil el relato, eliminando algunos versos ciertamente superfluos, manteniendo lo fundamental de la trama y con algunas aportaciones valiosas (véase, por ejemplo, el final: "A este tiempo los hermanos / con cara de agarrapiña / le arrebataron las cuerdas...»). ${ }^{25}$

El segundo fragmento lo recitó Ramón Bernal Ventura, de 90 años, de Alajeró, y fue recogido por los mismos recopiladores el 18 de agosto de 1983. Corresponde a

\footnotetext{
${ }^{24}$ Trapero remite en sus notas al texto completo del romance publicado en el Romancero General de Duran y reproduce la nota de Durán sobre el origen oriental del cuento que aportamos al final de este artículo. Para los romances de La Gomera procedentes de pliegos, véase Mendoza (2001). Salazar (2003) analiza las implicaciones de que la mayoría de los romances vulgares gomeros tengan su origen en pliegos de cordel y destaca el grado admirable de tradicionalización que ha alcanzado este tipo de textos que parten de fuentes escritas.

${ }^{25}$ Trapero anota, sin embargo, con severidad, a propósito de esta versión: «Esta versión es un buen ejemplo de la deformación fonética y léxica a que han llegado muchos romances gomeros; de los muchos «sinsentidos» de que están llenas algunas de sus versiones; de lo difícil que es entender - y transcribirlos textos romancísticos de La Gomera y, en fin, de que muchos de sus transmisores repiten y repiten palabras que no saben lo que dicen. En todo caso, buen ejemplo del funcionamiento de la transmisión oral, incluso en los romances que tuvieron su origen en la escritura de unos pliegos dieciochescos. Claro, que Ángel Cruz es el ejemplo paradigmático de los cantores de romances gomeros que más incomprensibles hacen sus versiones» (2000: 399).
} 
solamente 20 versos extraídos del inicio de la Segunda Parte (vv. 1-30) del romance, que empiezan con: «Lleno de horror y de espanto / quedó en la torre el mancebo / sin tener norte ni hacienda [ = senda, en $L P E$ ] / para salir del encierro». Más 4 versos tan sólo del inicio de la Tercer Parte (vv. 1-4): «Teniendo la hermosa Infanta / sus gustos ya conseguidos, / de su gargantilla y dueño / que la libró del peligro...». Trapero menciona como tercera versión del romance la de Jacinto Clemente Aguiar, de 86 años, de El Estanquillo (ay. Hermigua). Esta versión no está recogida, porque Jacinto, quien también se sabía este romance, lo contaba «prosificado, saltando de un episodio a otro y sin sujetarse a un modelo discursivo». ${ }^{26}$

\section{BALANCE Y FILIACIONES}

Los argumentos y el tratamiento de los distintos motivos de las diversas versiones de romances y cuentos examinadas, además de sus diferentes procedencias (cuentos castellanos, catalanes, filipinos, árabes) y géneros (en verso y en prosa; impresos y recitados, firmados y tradicionalizados), hacen francamente difícil deducir un entramado claro de filiaciones, si es que estas existieron en todos los casos. Reducimos la nómina a seis textos, para los que emplearemos títulos abreviados en este balance: 1001 Noches, LPE, 7 colores, Mercè, Clotilde y Tiñoso.

La parte primera de $L P E$ es sin duda la más original y también la más extraña por falta de lógica y trabazón. La secuencia [1] [Princesas liberadas y hermano traicionado] no se da, en efecto, ni en las 1001 Noches, ni en 7 colores, ni en Mercè, que siguen el mismo inicio argumental de la «Historia del undécimo capitán de policía» de 1001 Noches. El encierro de las princesas en la torre por parte de su cruel padre, en $L P E$ y Clotilde, podría tener alguna explicación si la hija fuera una. Sería el tema clásico de Dánae, encerrada inútilmente por su padre Acrisio en torre de bronce, para evitar que le diera un nieto que, según los oráculos, le había de asesinar. O el intento incestuoso de mantener a la hija viva y para sí, cerrada al exterior, como en el romance de Delgadina. Pero al ser tres hijas, se pierde esa motivación. La ilación de este tema con el de los caballos mágicos — que se vincularían a los inicios del cuento ATU, 530 (The Princess on the Glass Mountain), que combina habitualmente con ATU, 314tampoco está entretejida con una mínima lógica (ni siquiera dentro de la lógica del cuento folclórico). Tal vez por eso la versión de Clotilde, tan apegada en lo restante a $L P E$, trata de proporcionarle esa motivación al injustificado comportamiento del padre, cargando la culpa sobre el viejo mago — como el pérfido visir de las historias orientales-, amigo del rey y enamorado lúbricamente de la joven princesa. La

\footnotetext{
${ }^{26}$ Muy relevante es conocer que el mismo informante, Jacinto Clemente Aguiar, que ha memorizado el fragmento (tercera versión) de $L P E$, recuerda también un fragmento de veinte versos de «Los doce pares de Francia», correspondiente a la tercera parte de las seis de que consta el romance completo en su versión de pliegos de cordel (Trapero: 396-398; núm. 100). Y el hermano de Clemente, Darío, recuerda otros veinte versos, en su caso de la quinta parte. Hay, finalmente, una tercera versión recogida, de otro informante de La Gomera, que recuerda también un fragmento de la tercera parte de «Los doce pares». Como ya indicaba Menéndez Pidal, «Los doce pares de Francia» es el romance vulgar más difundido en pliegos en el siglo XVIII, y Trapero señala que en Canarias es el romance de pliego más extendido y conocido, aunque haya ya pocos informantes capaces de recordar episodios enteros. El pliego de cordel, como en el caso de $L P E$, sería el vehículo por el que entraron las distintas partes del romance en la tradición oral de las Canarias. Otro tanto sucedería con romances recogidos por Trapero, como el de Jacinto del Castillo (núm. 103), del que Ángel Clemente memoriza hasta 234 versos; el de Don Patricio de Córdoba y Aguilar (núm. 104), El cautivo de Gerona (núm. 105), El cautivo de Granada, procedente del pliego de Don Juan de Torres Cabrera (núm. 106); así como otros de bandidos, valientes y guapos, etc. Y, por supuesto, con todo el género de romancero vulgar y nuevo, procedente de pliegos de cordel.
} 
frustración del mago explicaría, en Clotilde, el castigo y la magia: no sólo el vengativo encierro, sino los caballos y collares mágicos. Esa explicación «lógica» confirma que el relato de $L P E$ se leyó o escuchó, pero además se modificó para su mejor comprensión, como hace la mejor tradición oral.

El punto de partida de todo cuento, como nos enseñó Propp, es la agresión al héroe (o la negación de su derecho). Ésta genera una degradación, que pone al protagonista y el relato en funcionamiento. El rescate de las princesas le permitirá al héroe disminuido, en $L P E$, revelar sus capacidades, mermadas por culpa de ser el hijo menor. El relato bíblico de José, inteligente y dotado, vendido por sus hermanos, pero convertido luego en su salvador, es una historia henchida de motivos folclóricos de cuento maravilloso, pero a la vez posee un fuerte contenido didáctico, relacionado con la mejor adaptación a la flexibilidad en los sistemas de parentesco (Camarena, 20052006: 36). Ese punto de partida se mantiene en la versión filipina de Clotilde, que sigue claramente la primera parte del pliego de $L P E$, pero después de haber incorporado al personaje motivador del mago. En ambas versiones el héroe sin credenciales, Juan, como el José del Génesis, demostrará inteligencia, astucia, autoridad y valor superiores a los de sus hermanos. Sin embargo, 7 colores y Mercè sustituyen esa historia de inferioridad en el linaje por otra relacionada, como hemos dicho, con la versión de 1001 Noches, de desposesión de la herencia legítima del primogénito por culpa de una madrastra cruel que ha engañado a su padre, distorsionado su raciocinio y capacidad para el buen gobierno. El elemento salvador es siempre, en unas versiones u otras, el caballo mágico, que luego se convertirá en ayudante perfecto. El caballo mágico permite la huida chamánica (Eliade), el pasaje al Más Allá, donde el héroe podrá empezar una nueva vida. El traslado al otro mundo es el eje del cuento maravilloso y el caballo es, entre todos, el principal de los dones y ayudantes encantados con los que cuenta el héroe (Propp, 1974: 241-277).

A partir de la sección [2] [Huida del héroe con el caballo mágico], es decir de las partes segunda y tercera de $L P E$, se presentan mayores coincidencias argumentales entre todas las versiones presentadas. De un lado, tenemos un tipo común (ATU, 314, The Goldener), cuyo molde prácticamente se repite en todos los cuentos (menos en Clotilde, pero porque corresponde a la primera parte de $L P E$ ). El héroe vence sus carencias de partida ayudado por su caballo mágico y mediante el recurso del disfraz para poder introducirse en la nueva corte. Una vez conseguido su objetivo de matrimonio, no bastará. Tendrá que luchar por legitimar la validez de éste, obteniendo los remedios mágicos que han de curar al padre de la princesa que pretende. Y aquí sí que habrá plena coincidencia entre LPE, 1001 Noches, 7 colores, Mercè, Clotilde y Tiñoso.

Propp (1974: 193-200) estudió, en Las raices históricas del cuento, dentro del capítulo de «La cofradía del bosque», cómo se relacionan, en el tema del héroe no reconocido a su regreso, los motivos del «suciote» (aquí sería el tiñoso), con el de las respuestas negativas (el «I don't know», que permite el incógnito) y con el motivo de la cabeza cubierta (con gorro) o descubierta (con calva). El héroe va sucio, se cubre de cenizas (se ha hablado del héroe de ATU, 314, como variante masculina de Cenicienta), y muestra su vigor (cabello largo) o se identifica como futuro marido (con el gorro), en la visión antropológica proppiana, como parte iniciática preparatoria de la ceremonia de matrimonio. En el tipo 314, «The youth covers his Golden hair, pretending to be a scaldhead and takes service in the king's court as a gardener. [K.1816.1]». El disfraz es obligatorio, si el héroe se quiere introducir en la corte y, además, sirve para acentuar su inferioridad y hacer más sorprendente luego su revelación. La marca distintiva o el 
disfraz (el pelo dorado, oculto bajo el gorro, en Goldener, la tiña o la calva) son marcas de impotencia, pero también de necesaria espera. Implican un estigma de condena, pero también una esperanza de salvación: castigo por la trasgresión (en ATU, 314, franquear la habitación prohibida), pero salvación porque el disfraz permite temporalmente ocultar la personalidad para conseguir el objetivo.

El disfraz del héroe (la ocultación del pelo, revelador de vigor y potencia), haciéndose pasar por calvo o tiñoso ( 7 colores, Mercè) se imbrica con la entrada en el palacio al servicio del rey como jardinero (Aa-Th, 3104: Gardener; 1001 Noches y 7 colores), ganadero (LPE), boyero (1001 Noches: jardinero y boyero), huertano (Mercè) o granjero (Clotilde). El héroe de $L P E$ se disfraza o hace pasar, además, por simple o loco («Juanillo el loco»). Y también se cubre la cabeza con piel de cordero para esconder su identidad, como si fuera un tiñoso. En 7 colores es donde más se resalta el papel del gorro encubridor e identificador: por el lado azul le hará parecer bello y rico, mientras que por el lado rojo parecerá necio y repugnante. Solamente en dos versiones se incide en el motivo de la respuesta estúpida («I don't know»): 'Gracias, gracias', «Mercè, Mercè», (Mercè) o "Quizás sí, quizás no» ( 7 colores). Reticencias que no están muy distantes de la simulación como «Juanillo el loco» en LPE. En el tipo internacional, la princesa ve al muchacho, pese a las apariencias u ocultación de sus rasgos distintivos, en su verdadera personalidad («as a golden hair knight») (en 7 colores), se enamora de él y lo escoge como marido, o bien ofreciéndole o tirándole una manzana dorada (en el tipo original). «Golden Apple» que puede ser un pañuelo (1001 Noches), un par de peras (LPE y Mercè), dos rosas de oro (7 colores) o una granada dorada (Clotilde).

Pero la versión de $L P E$ demuestra en esta sección su compleja articulación. Porque la princesa exige no una, sino dos pruebas para identificar de manera infalible a su pretendiente: victoria en el torneo y coincidencia con la gargantilla entregada en la torre como objeto reconocedor. La victoria en el torneo juega de nuevo con la ley del tres: con una primera cerda de su caballo mágico, aparece un caballo bien enjaezado con dos sirvientes con los que gana el torneo; con la segunda cerda, aparece otro caballo con seis criados con sus libreas; con la tercera, un caballo negro con doce criados, de terciopelo rojo. Se observa un in crescendo: dos, seis y doce criados. El color del caballo - Propp insiste en la importancia del pelaje del caballo, así como en su naturaleza ígnea- sólo se menciona en el tercero, en $L P E$, pero en Mercè jugará mayor papel: caballo blanco (el color o no-color de la perfección) para ejército de caballos negros, caballo negro para ejército de caballos blancos. 7 colores, en cambio, pese al título del cuento, no repara en detallar los colores del caballo. El tipo internacional no presenta el torneo, pero las versiones hispánicas, sí. El rey no tiene más remedio que aceptar su promesa de casar a su hija pequeña, pero no puede evitar castigarla, desterrándola a un recinto inapropiado (ATU, 314), que puede ser «rústico pabellón de madera» (7 colores), habitáculo del huerto (Mercè), etc. Y también coincidirá con el tipo ATU, $314(<\mathrm{AT}, 532)$ lo que sigue en la tercera parte de $L P E$ y en casi todas las versiones.

Llegamos así a la sección [4] [El héroe ayuda al rey: superación de tres pruebas]. El rey requiere el auxilio de sus yernos «legitimados» hasta en tres ocasiones y el héroe se adelantará las tres veces, obteniendo, con la colaboración de su caballo mágico, los objetos mágicos para curar una enfermedad o salvar el reino antes que los yernos, demostrando su mayor valía, siempre de incógnito. Las narraciones orales subordinan cualquier elemento descriptivo o introspectivo a lo narrativo. En vez de 
describir, el cuento señala o subraya cosas importantes mediante la repetición, normalmente de tres (tres hermanos, tres pruebas, tres prendas...). Las pruebas para salvar al rey cumplen en ATU, 314 la Ley del tres. En $L P E$, las dos primeras consisten en la obtención de remedios mágicos para curar sendas enfermedades (ceguera y debilitamiento extremo) y la tercera en la ayuda contra los enemigos en una batalla. Ese orden de $L P E$ se mantiene, salvo en Mercè, donde las guerras van primero y la ceguera y debilidad después. 7 colores presenta en vez de ceguera (individual), una epidemia (colectiva), y en vez del debilitamiento (individual), una plaga (colectiva), como si pretendiera reproducir en pequeño - acota Amores - los males de las plagas del Apocalipsis. Los remedios coinciden: agua de la Bella Fuente (Mercè), agua de la fuente de Esclavonia ( $L P E)$, o agua azul de la Fuente de los dos mármoles ( 7 colores) para la ceguera ( $L P E$ y Mercè), o para la plaga (7 colores); leche de leona (LPE, Mercè, Tiñoso), como la leche de osa del cuento de 1001 Noches, o bien leña de la Selva de los gigantes ( 7 colores), para la enfermedad más genérica.

Las compensaciones serán también asimilables: a cambio del agua mágica, dos peras ( $L P E$ y Mercè), dos rosas de oro ( 7 colores); a cambio, de la leche de leona, ser desorejados ( $L P E, 7$ colores); y, finalmente, a cambio de los pendones o banderas ganados en la batalla, recibir el estigma de esclavitud con un hierro candente ( $L P E, 7$ colores, Mercè, Tiñoso). Un acto de degradación del que burla claramente la versión mallorquina, Mercè, al regodearse en que se les marcó en las nalgas. Este final común es importante. Los elementos anteriores estaban anotados en el tipo internacional ATU, 314: «He obtains the magic remedy (e.g. milk of a bird, water of life) for the king who had grown blind, kills a dragon, and defeats a foreign army three times in disguise». Pero este final, no. Aunque confirma el final del tipo: "Goldener's identity is revealed (e.g. by wounds, brands) and his true status is recognized».

El juego de remedios y compensaciones en los distintos cuentos se resumiría así:

\begin{tabular}{|c|c|c|c|}
\hline \multicolumn{2}{|c|}{1001 Noches: } & 4b (Leche de osa) & \\
\hline$L P E$ & $\begin{array}{l}\text { 4a (Leche de leona) } \\
\text { desorejados }\end{array}$ & $\begin{array}{l}\text { 4b (Agua mágica) } \\
\text { dos peras }\end{array}$ & $\begin{array}{l}\text { 4c (Ayuda militar) } \\
\text { hierro candente }\end{array}$ \\
\hline 7 colores: & $\begin{array}{l}\text { 4a (Leña de la Selva) } \\
\text { desorejados }\end{array}$ & $\begin{array}{l}\text { 4b (Agua mágica) } \\
\text { dos rosas de oro }\end{array}$ & $\begin{array}{l}\text { 4c (Ayuda militar) } \\
\text { hierro candente }\end{array}$ \\
\hline Mercè: & $\begin{array}{l}4 \mathrm{c} \text { ( } 2 \text { veces, Ayuda militar }) \\
\text { flecha }\end{array}$ & $\begin{array}{l}\text { 4b (Agua mágica) } \\
\text { dos peras }\end{array}$ & $\begin{array}{l}\text { 4a (Leche de leona) } \\
\text { hierro candente }\end{array}$ \\
\hline Tiñoso: & -- & -- & $\begin{array}{l}\text { 4a (Leche de leona) } \\
\text { hierro candente }\end{array}$ \\
\hline
\end{tabular}

Por tanto, para toda esta segunda parte (pliegos $2 .^{\circ}$ y $3 .^{\circ}$ en $L P E$ ) podemos hablar ciertamente de un tratamiento común, que se encuentra mejor desarrollado en las tres versiones hispánicas ( $L P E, 7$ colores y Mercè) y en la filipina (Tiñoso) que en el cuento de 1001 Noches. A partir de aquí, se puede especular todo lo que se quiera sobre las posibilidades de filiación de estas versiones. Cronológicamente, hay unos datos que denotan inequívocamente la mayor antigüedad de los pliegos de $L P E$, que datan de la segunda mitad del siglo XVIII en sus primero testimonios conservados. Además, conocemos que fueron muy difundidos por toda la Península. No sabemos si llegarían a América, pero sí que lo hicieron a las Islas Canarias y sospechamos con bastantes fundamentos que también a las Filipinas. Contamos, en consecuencia, con una alta probabilidad de que el romance fuera leído, memorizado, trasformado, y pasara, por una parte a la tradición oral (Mercè), y se siguiera transformando, por otra, en la tradición escrita (7 colores). Ambas tradiciones lo quisieron y pudieron adaptar de manera 
libérrima. Sin embargo, y puesto que desconocemos el origen de su argumento (aparte de que la relación con el del cuento de 1001 Noches añadido por Mardrus pueda abrir vías hacia textos más antiguos), no podemos descartar la posibilidad de que circularan una o varias otras versiones, hoy por hoy desconocidas, que sirvieran de fuente a las cuatro mencionadas (y a un quinta también, si incluimos el cuento de 1001 Noches).

La mayor dificultad para aceptar la hipótesis de un texto -llamémosleprinceps, el de $L P E$, del que deriven los restantes, reside en que la primera parte de $L P E$ está excluida de los desarrollos de las otras versiones. Ahora bien, solamente $L P E$ cubre un desarrollo legendario cercano al mundo carolingio: empezando por el nombre de Clotaldo y siguiendo por las tres princesas, el castillo o torre en alto, el héroe rescatador, auxiliado por el caballo extraordinario, que puede no sólo saltar prodigiosamente, sino, como en tantas leyendas de Roldán, incluso volar. Asimilado, eso sí, al de los cuentos orientales: el caballo no sólo habla, sino que concede favores, como un genio encantado. $^{27}$

\section{CONCLUSIÓN}

El romance de $L P E$ es, en conclusión, un verdadero cuento maravilloso, sólo que dispuesto en rima de verso romance. Se puede considerar realmente uno de los primeros testimonios de cuento de hadas o fairy tale de la historia de la literatura española. Y, si no coincide estrictamente con un cuento concreto, sí resulta perfectamente identificable con la conjunción suficientemente trabada de una serie de motivos de dos cuentos -ATU, 301 y ATU, 314- muy bien articulados y perfectamente representados como tipos fijos en la tradición folclórica hispánica y universal. $L P E$ es un cuento, o un doble cuento, firmado, no anónimo. Pero, pese a que su firma corresponde a la de un meritorio artesano de la escritura romanceril, Alonso de Morales, el romance nació y se difundió como uno más de esos numerosos y populares relatos versificados y anónimos que fueron leídos, escuchados e incluso, a veces, transmitidos oralmente gracias a la popularidad de los pliegos sueltos o pliegos de cordel que se imprimieron entre los siglos XVIII y XIX. No resulta extraño, tratándose de un representante de ese género, que lo encontremos, en pleno siglo $\mathrm{XX}$, recitado de memoria, si bien parcialmente —algo lógico, dada su considerable extensión- entre otros romances recogidos en La Gomera. En la bella isla canaria, la memoria y la voz han mantenido vivas en la oralidad hasta hace nada — quizás todavía excepcionalmente hasta hoy- las palabras de unos pliegos que habían dejado de imprimirse desde hacía décadas.

Poco más podemos decir de sus orígenes, aunque la profundización en las fuentes de los muchos testimonios que Uther aporta de ATU, 301 y 314, empezando por las fuentes de la «Historia del undécimo capitán de policía» de Las mil y una noches, podrá deparar en un futuro, a buen seguro, algunas nuevas pistas o certezas. A la vista de la concentración de ingredientes originales y aparentemente exóticos o foráneos, Agustín Durán, cuando editó el romance en su Romancero general (1849-1851), sin mencionar Las mil y una noches, dejó la siguiente nota a pie de página, tan reveladora e intuitiva como intrigante:

He aquí algunos de los poquísimos romances, pero modernos y del siglo pasado, que se hallan directamente hechos sobre los cuentos ó consejas orientales, que los árabes nos transmitieron y dejaron tan impresos en la memoria, que desde tiempos muy remotos han servido en el hogar doméstico y en boca de los ancianos para recreo de las familias. Lo

\footnotetext{
${ }^{27}$ Para una panorámica sobre las leyendas de Roldán, ibéricas y románicas, véase Pedrosa (2001).
} 
raro es que siendo muy populares entre nosotros, haya tan pocos escritos, impresos y versificados, y que hayan quedado, por decirlo así, únicamente confiados a la tradición oral. (Durán, 1926, II: 251)

Y es que tantos motivos folclóricos originales, variados y exógenos recuerdan, de hecho, además de los de algunos de los tipos y motivos de fairy tales mencionados, los de narraciones caballerescas breves, como París y Viana (el rescate de la doncella y la ayuda al padre de ésta) o Clamades y Clarmonda (el caballo mágico volador), o Roberto el Diablo, que hemos mencionado, de origen medieval u oriental. Si bien no son tampoco ajenos a la temática genérica de los pliegos sueltos de los siglos XVIII y XIX los conflictos familiares (de la realeza), ambientes medievalizantes, bélicos y exóticos (orientales), tramas más o menos bizantinas de secuestros, encierros, rescates y anagnórisis, etc. Todo ello, desde el cuento oriental y fantástico, hasta el relato ejemplar o edificante, es capaz de amalgamarlo ese género proteico que es el pliego suelto y, a su servicio, algún poeta menor, de no muy altos vuelos, aparentemente especializado en escritura de versos pomposos e irónicos, que lograban con éxito sus objetivos de entretenimiento. Sin embargo, tal vez nunca sepamos hasta qué punto este Alonso de Morales, que firma el romance de $L P E$, y que aparece firmando también, entre otras, una versión en romance, en seis partes, de La española inglesa, la novela ejemplar de Miguel de Cervantes, pudo ser consciente o intuir las dificultades de encaje en la historia de la literatura que su curiosa producción iba a provocar, doscientos años más tarde.

\section{BIBLIOGRAFÍA}

Aguilar Piñal, Francisco (1972): Romancero popular del siglo XVII, Madrid, CSIC.

AMORES GARCÍA, Montserrat (1997): Catálogo de cuentos folclóricos reelaborados por escritores del siglo XIX, Madrid, CSIC.

Amores García, Montserrat (2001a): Fernán Caballero y el cuento folklórico, El Puerto de Santa María, Ayuntamiento.

Amores García, Montserrat (2001b): «Cuentos de vieja, de Juan de Ariza: la primera colección de cuentos folclóricos españoles», Scriptura, 16, pp. 25-46.

Amores García, Montserrat (2002): «Dos versiones literarias andaluzas del cuento de 'Juanillo el Oso'», Garoza, 2, pp. 45-64.

Amores GarcíA, Montserrat y AMORES, Teresa (2014): «El cuento folclórico al servicio de la moral en el Semanario Pintoresco Español», Castilla, 5, pp. 458480

Ashliman, D. L.: Rapunzel and Other Folktales of Aarne-Thompson-Uther Type 310. URL: <http://www.pitt.edu/ dash/type0310.html>.

Ashliman, D. L. (2015): «Philippine Tales», en_Folktales and Fairy Tales: Traditions and Texts from around the World, $2^{\mathrm{a}}$ ed. revisada, Anne E. Duggan y Donald Haase, con Helen Callow, Westport, Greenwood, 5 vols., vol. II, pp. 774-776.

Baquero Goyanes, Mariano (1992): El cuento español. Del Romanticismo al Realismo, Madrid, CSIC. 
CAmarena, Julio (2005-2006): "La tradición oral en el Antiguo Testamento. La herencia de los Patriarcas-Profetas (II)», Estudos de Literatura Oral, 11-12, pp. 33-50.

Camarena, Julio y Chevalier, Maxime (1995): Catálogo tipológico del cuento folklórico español. Cuentos maravillosos, Madrid, Gredos.

CARo BAROJA, Julio (1990): Ensayo sobre la literatura de cordel [Madrid, Revista de Occidente, 1969], Madrid, Istmo.

CARruthers, Amelia (2015): Rapunzel and Other Fair Maidens in very Tall Towers, Cookhill, Alcester, Pook Press.

Casas Delgado, M. Inmaculada (2012): Romances con acento andaluz. El éxito de la prensa popular (1750-1850): Sevilla, Centro de Estudios Andaluces.

Casas Delgado, M. ${ }^{a}$ Inmaculada (2015): «Semblanza de Rafael Rodríguez y Cuenca (17i?-1844)», en EDI-RED / Portal Editores y Editoriales Iberoamericanos (siglos XIX-XXI) / Biblioteca Virtual Miguel de Cervantes.

Chozas Ruiz-Belloso, Diego (2005): «La literatura de cordel brasileña y sus conexiones con la Edad Media», Espéculo. Revista de estudios literarios, 30. URL: <http://www.ucm.es/info/especulo/numero30/cordelbr.html>

De La CAMPa GutiÉRrez, Mariano (2007): «El Romancero nuevo entre neoclásicos y románicos», en Actas del XVI Congreso de la Asociación Internacional de Hispanistas (París, 9-13 julio 2007): vol. 2 [CD-ROM]

Donoso JimÉneZ, Isaac (2007): «El Islam en las Letras Filipinas», Studi Ispanici, 32, pp. 291-313.

DONOSO JiMÉNEZ, Isaac (2011): «El Renacimiento europeo en la formación de la literatura clásica de Filipinas», eHumanista, 19, pp. 407-425.

Donoso JIMÉNEZ, Isaac (2012): «El Barroco filipino», en Isaac Donoso, ed., Historia cultural de la lengua española en Filipinas: ayer y hoy, Madrid, Verbum, 2012, pp. 85-145.

Donoso JiMÉNEZ, Isaac (2015): «En Joan Tinyós: estudi i traducció d'un romanç filipí del Regne de València», Lemir, 19, pp. 583-636.

DURÁn, Agustín (1926): Romancero General o Colección de romances castellanos anteriores al siglo XVIII, 2 vols., Madrid, Librería y Casa editorial Hernando.

Eliade, Mircea (1976): El chamanismo y las técnicas arcaicas del éxtasis, México, F.C.E.

Eugenio, Damiana L. (1987): Awit and Corrido. Philippine Metrical Romances, Quezon City, Universidad de Filipinas.

FANSLER, Dean S. (1921): Filipino Popular Tales. Collected and Edited with Comparative Notes, Lancaster, PA, American Folk-Lore Society.

Fradejas Lebrero, José (ed.) (1981): Sendebar. Libro de los engaños de las mujeres, Madrid, Editora Nacional.

García De EnTERríA, M. ${ }^{\mathrm{a}}$ Cruz (1973): Sociedad y poesía de cordel en el Barroco, Madrid, Taurus, 1973.

GARCíA De EnTERríA, M. ${ }^{a}$ Cruz (1983): Literaturas marginadas, Madrid, Playor.

Gies, David T. (1975): Agustín Durán: A Biography and Literary Appreciation, Londres, Tamesis.

GoldBerG, Harriet (2000): Motif-Index of Folk Narratives in the Pan-Hispanic Romancero, Tempe, Arizona Center for Medieval and Renaissance Studies. 
Gomis Coloma, Juan (2015): Menudencias de imprenta. Producción y circulación de la literatura popular (Valencia, siglo XVIII), Valencia, Institució Alfons el Magnànim.

HERNÁNDEZ FERNÁNDEZ, Ángel (2006): «El cuento del fortachón en el folklore y la literatura», Culturas Populares. Revista Electrónica, 2 (s. p.).

LACARrA, M. ${ }^{a}$ Jesús (ed.) (1989): Sendebar, Madrid, Cátedra.

LumberA, Bienvenido L. (1986): Tagalog Poetry 1570-1898. Tradition and Influences in its Development, Quezon City, Ateneo de Manila University Press.

MARCO, Joaquín (1977): Literatura popular en España en los siglos XVIII y XIX (Una aproximación a los pliegos de cordel), Madrid, Taurus, 2 vols.

Mendoza Díaz-Maroto, Francisco (2001): Panorama de la literatura de cordel española, Madrid, Ollero \& Ramos.

Mendoza DíAz-Maroto, Francisco (2003): «Observaciones sobre los romances recogidos en La Gomera procedentes de pliegos sueltos», en El romancero de La Gomera y el romancero general a comienzos del tercer milenio, ed. Maximiano Trapero, Tenerife, Cabildo Insular de La Gomera, pp. 295-314.

Mojares, Resil B. (1983): Origin and Rise of the Filipino Novel: A Generic Study of the Novel until 1940, Quezon City, University of the Philippines Press.

Pedrosa, José Manuel (2001): «Roldán en las leyendas ibéricas y occidentales», Garoza: revista de la Sociedad Española de Estudios Literarios de Cultura Popular, 1, pp. 165-190.

Pedrosa, José Manuel (2006): «Mirra en su árbol, Delgadina en su torre, la mujer del pez en su pozo: el simbolismo arriba/abajo en los relatos de incesto», Revista de Folklore, 312, pp. 183-194.

Porro Herrera, M. a J. (2000): «Imprenta y lectura en Córdoba (1556-1900)», Arbor, 654, pp. 253-275.

Porro Herrera, M. ${ }^{a}$ J. (2002): «La española inglesa cervantina en dos pliegos de cordel», Boletín de la Real Academia de Córdoba de Ciencia, Bellas Letras y Nobles Artes, 141, pp. 271-290.

DOI: https://doi.org/10.3989/arbor.2000.i654.1013

PROPP, Vladimir (1974): Las raíces históricas del cuento, Madrid, Fundamento.

RAMÓN VAllejo, José y GonzÁlez, José Antonio (2014): «Las caballerías en la etnomedicina española: remedios y simbolismos asociados», Revista de Folklore, 384, pp. 39-56.

RAMOS, Rafael (2005): «Texto compilador y códice: el relato final del Libro de los engaños», en Historicist Essays on Hispano-Medieval Narrative. In Memory of Roger M. Walker, eds. Barry Taylor y Geoffrey West, Londres, Maney Publishing for the Modern Humanities Research Association, pp. 386-407.

Rodríguez GutiÉRrez, Borja (2004): Historia del cuento español (1764-1850), Madrid-Frankfurt, Iberoamericana-Vervuert.

Rubio Cremades, Enrique (1995): Periodismo y literatura: Ramón de Mesonero Romanos y el Semanario Pintoresco Español, Alicante, Institut de Cultura Juan Gil-Albert.

SALAZAR, Flor, (2003): «El romancero vulgar en La Gomera», en El romancero de La Gomera y el romancero general a comienzos del tercer milenio, ed. Maximiano Trapero, Tenerife, Cabildo Insular de La Gomera, pp. 219-246. 
Trapero, Maximiano (2000): Romancero General de La Gomera, 2. ${ }^{\mathrm{a}}$ ed., La Gomera, Cabildo Insular.

Vernet, Juan, ed. (1999): Las Mil y Una Noches, Barcelona, Planeta.

Fecha de recepción: 10 de septiembre de 2016

Fecha de aceptación: 21 de septiembre de 2016

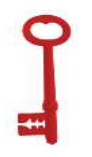

